\title{
Estratigrafía e inversión tectónica del 'rift' neógeno en el Campo del Arenal, Catamarca, NO Argentina
}

\author{
Gerardo E. Bossi ${ }^{1}$, Claudia M. Muruaga ${ }^{1}$
}

1 Instituto de Estratigrafía y Geología Sedimentaria Global (IESGLO), Facultad de Ciencias Naturales e Instituto Miguel Lillo, Universidad Nacional de Tucumán, Miguel Lillo 205 (4000) Tucumán, Argentina.

gbossi@csnat.unt.edu.ar; iesglount@csnat.unt.edu.ar

\begin{abstract}
RESUMEN. La cuenca de Santa María-Hualfín en las Sierras Pampeanas del NO de Argentina, comenzó con el fallamiento por extensión de un gran domo orientado NNO-SSE desarrollado sobre basamento cratonizado y peniplanizado. Los bloques fallados adoptaron un diseño basculado hacia fuera del eje del domo preservado hoy en día por la posición de la penillanura. El relleno inicial paleógeno (formaciones Hualfín y Saladillo) aparece asociado a una serie de depocentros asimétricos controlados por fallas normales. Con el ingreso de la sedimentación neógena (Grupo Santa María), se establece un diseño de hemigrábenes extensos y opuestos con depocentros hacia ambos bordes y rampa común en el eje del domo. La sedimentación alcanzó un máximo de $3.000 \mathrm{~m}$ en los depocentros cercanos a las fallas lístricas principales. Durante la evolución del domo pampeano ingresa un volcanismo activo intra- y pericuencal en el lapso 11-6 Ma relacionado con un ascenso de la astenósfera que determinó así mismo el engrosamiento de la litosfera y el cambio de régimen de la deformación superficial de extensional a compresiva. El punto de inflexión de este cambio está definido por la disconformidad intra Andalhuala que está fechada entre las tefras 4,8 y 5,2 Ma. La inversión tectónica asociada a una contracción este-oeste del orden de 9\%, produjo la formación de fallas inversas de alto ángulo y reactivación de otras normales, así como el ascenso sostenido de los bloques de basamento del borde de la cuenca, incluyendo la emergencia de algunos bloques intracuencales, quedando los depósitos cenozoicos reducidos a los valles y escasamente deformado.
\end{abstract}

Palabras claves: Estratigrafía del Neógeno, Sierras Pampeanas, Evolución cuencal y tectónica, Geología regional.

\begin{abstract}
Stratigraphy and tectonic inversion of the Neogene rift in Campo del Arenal, Catamarca, NW Argentina. The Santa María-Hualfín Basin in the NW Pampean Ranges started during the extensional faulting of a large NNW-SSE elongated dome, developed above a peneplained basement. The faulted blocks were tilted outwards from the axis of the dome. Subsequently, the Neogene sedimentation (Santa María Group) was concentrated along listric faults bounding hemigrabens, reaching up to 3,000 m thick in these areas. An intrabasin volcanic event occured during 11-6 Ma and was associated to asthenospheric upwelling and crustal thickening. A change from extensional to compressive tectonism, represented by the Intra-Aldalhuala disconformity, occurred at 4.8-5.2 Ma, resulting in approximately $9 \%$ shortening. Subsequently, during Pliocene times, thermal subsidence took place.
\end{abstract}




\section{Introducción}

La cuenca de Santa María-Hualfín (Bossi et al., 1993) involucra los depósitos cenozoicos que afloran en los bolsones de las Sierras Pampeanas Nordoccidentales (Fig. 1) desde Cafayate en Salta hasta la sierra de Belén al sur, las sierras de Capillitas y Aconquija y las Cumbres Calchaquíes al este y las sierras de Chango Real, Papachacra y Fiambalá por el oeste. La sucesión sedimentaria de las dos áreas, clásicas de afloramientos: Entre
Ríos (ex Chiquimil) en el valle de Santa María y Puerta de Corral Quemado, al suroeste de la sierra de Hualfín (Fig. 1) presentan grandes similitudes estratigráficas que han permitido establecer una sólida correlación (Stahlecker, 1926 in Marshall y Patterson, 1981; Bossi et al., 1987). Esta correlación permitió uniformar la nomenclatura estratigráfica (Fig. 2), siguiendo el esquema clásico de Stahlecker (in Marshall y Patterson, 1981) con los aportes de Peirano (1956), Galván y Ruiz Huidobro (1965) y Bossi y Palma (1982).

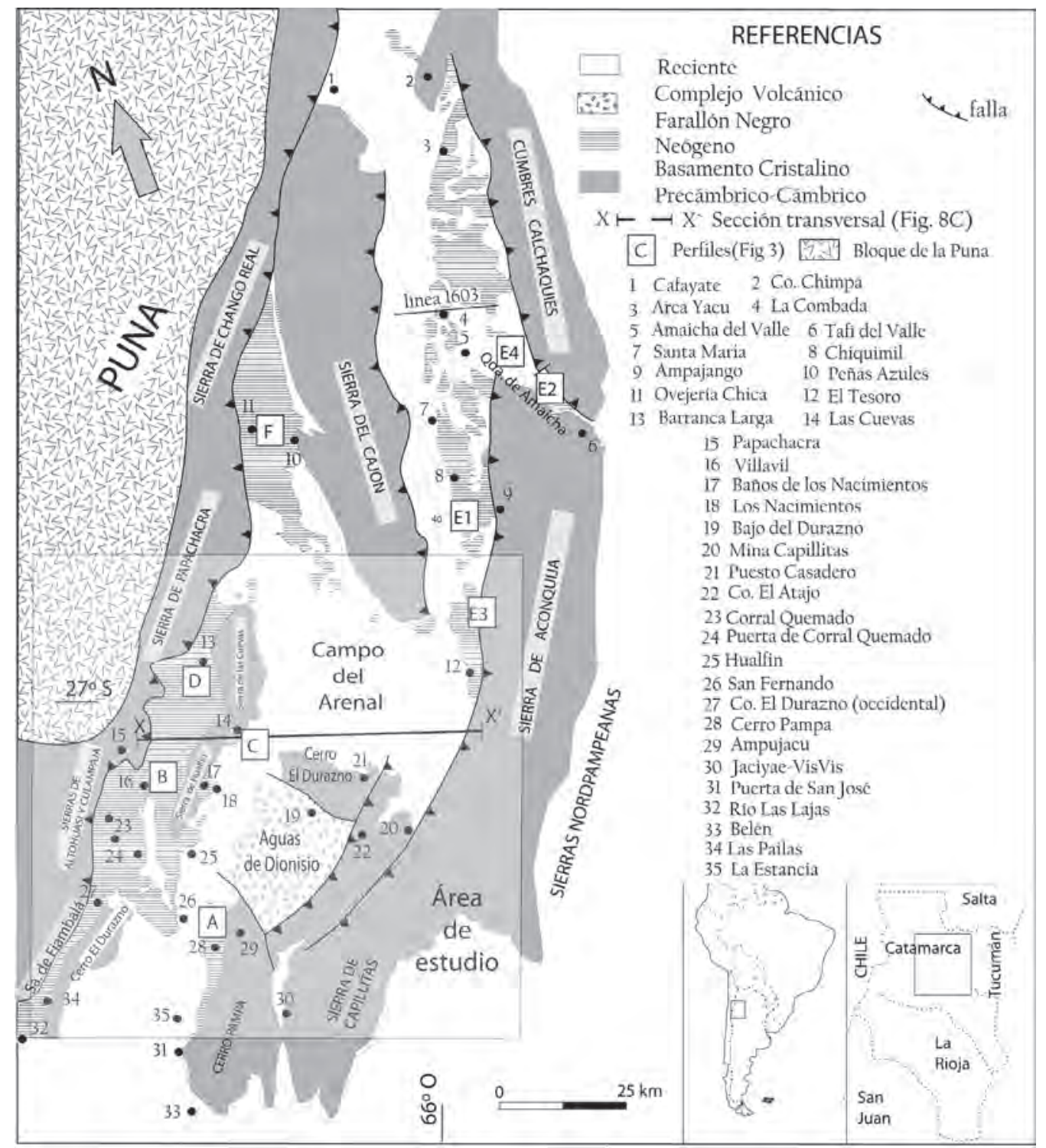

FIG. 1. Mapa de ubicación del área estudiada y localidades mencionadas en el texto. 


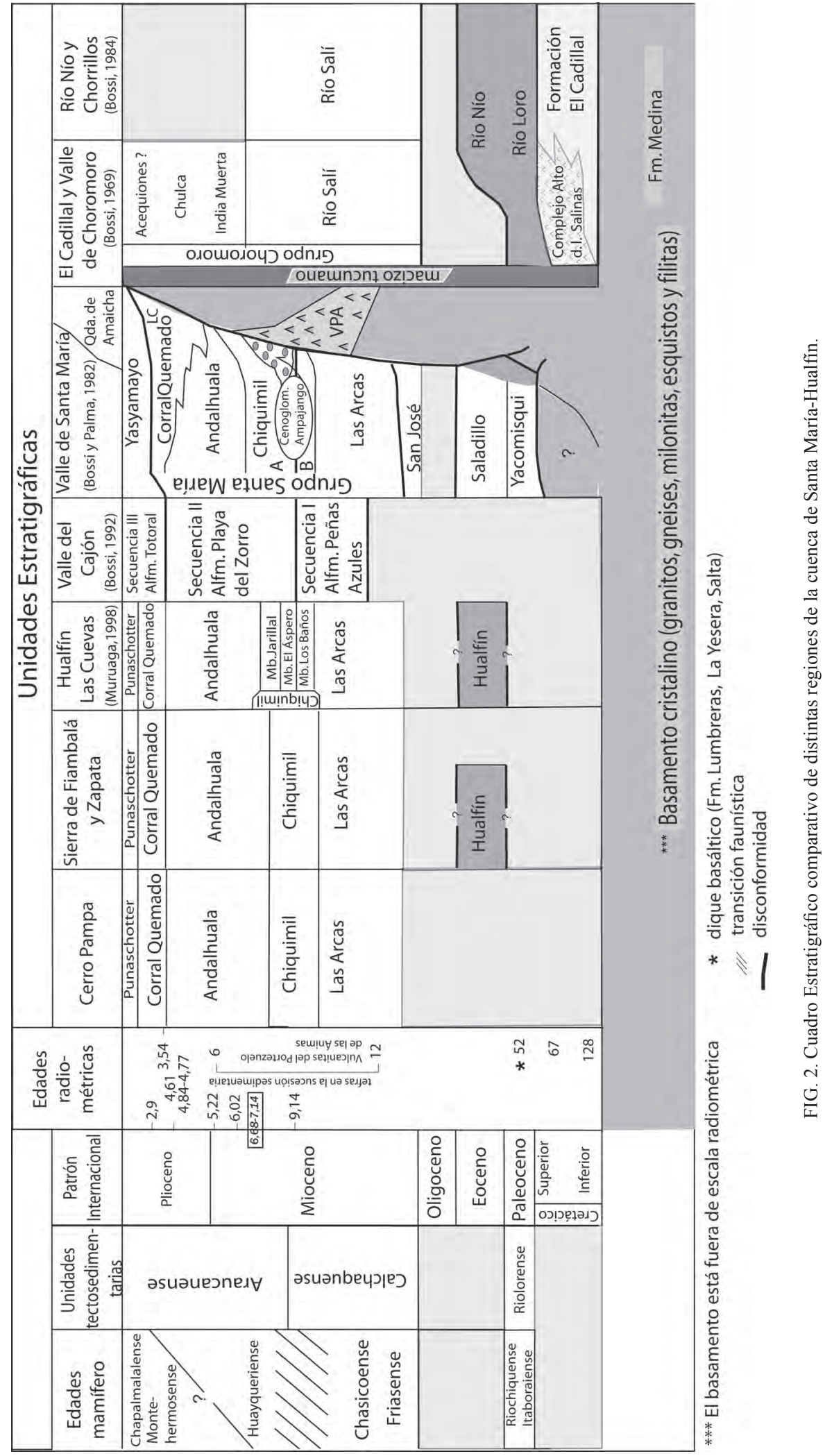


El objetivo principal de este trabajo es presentar el esquema litoestratigráfico más adecuado, junto con una descripción ordenada de las unidades reconocidas, sus particularidades más significativas y su interpretación ambiental. Así mismo, con el apoyo de las líneas sísmicas, se presenta un esquema de relleno de la cuenca basado en un modelo de 'rift' superficial asociado a fallamiento lístrico como resultado de un abovedamiento del basamento durante el Mioceno medio, seguido en el Plioceno de inversión tectónica, fallamiento inverso y elevación de bloques de montaña.

\section{Estratigrafía}

La sucesión sedimentaria aparece dividida en tres secciones con sustanciales diferencias litológicas (Fig. 2): 1. Formación Hualfín, 2. Grupo Santa María, integrado por las formaciones Las Arcas, Chiquimil, Andalhuala y Corral Quemado y finalmente, 3. Conglomerados de la Puna (Punaschotter). Desde el punto de vista de la evolución tectónica se pueden reconocer varios estadios que incluyen pre-'rift' (Hualfín), 'rift' inicial (Las Arcas), 'rift clímax' (Chiquimil y Andalhuala inferior), inversión inicial (Andalhuala superior y Corral Quemado) y clímax de inversión (Punaschotter). Pertenecen a este último grupo la Aloformación El Totoral (valle del Cajón, Bossi et al., 1992) y la Formación Yasyamayo (valle de Santa María, Bossi y Palma, 1982). El Cuadro Estratigráfico de la figura 2 resume la información cronológica y espacial de las unidades estratigráficas de la cuenca.

Los perfiles estratigráficos incluidos en la figura 3 han sido relevados con mucho detalle en áreas de afloramientos continuos. La ubicación aproximada de los mismos está indicada en la figura 1 . La correlación entre el perfil del cerro Pampa (A, Fig. 3) y de Villavil (B, Fig. 3) fue ajustada mediante determinaciones de isótopos ambientales $\left(\delta^{13} \mathrm{C}\right.$ y $\left.\delta^{18} \mathrm{O}\right)$ medidos en calcretos y rizoconcreciones (Muruaga et al., 2003). Estos perfiles fueron correlacionados mediante datos isotópicos y dataciones de tefras con los obtenidos en el valle del Cajón (datos inéditos). Sin embargo, existen grandes diferencias litoestratigráficas entre éstos y aquéllos, que ameritan el uso de una subdivisión diferente. El perfil de Villavil registra un espesor total acumulado que supera ligeramente los $3.000 \mathrm{~m}$, mientras que el perfil del cerro Pampa registra un espesor de $1.900 \mathrm{~m} \mathrm{y}$ numerosas disconformidades, algunas de las cuales son angulares. Los perfiles Las Cuevas (C, en las figuras 1 y 3 ) y Barranca Larga (D, en las figuras 1 y 3), fueron usados para estimar los espesores de las unidades contenidas en el subsuelo por la línea YPF 1549 (que sigue el perfil transversal X-X', Fig. 1) cuyo extremo oeste se encuentra bien próximo. Los diseños sísmicos observados en la línea y su posible relación con las litologías de superficie (apoyada con mediciones de densidad) fueron también considerados para ubicar los límites tentativos. Estos límites fueron seguidos lateralmente hacia el norte por el valle de Santa María, hasta la línea YPF 1603 (que pasa arriba de Amaicha del Valle, Fig. 4), donde también hay un perfil estratigráfico muy cercano. El ajuste de los espesores trasladados y los reales es razonablemente correcto.

El mapa geológico de la figura 5 fue realizado sobre una base georreferenciada mediante el programa ArcView 3.2 ${ }^{\circledR}$. Involucra todo el sector central y sur de la cuenca de Santa María-Hualfín y contiene información relevada en el campo, durante aproximadamente 20 años de trabajo.

\subsection{Peniplanicie Pampeana}

La peniplanicie pampeana constituye una unidad paleogeomórfica que se presenta como una superficie casi plana, con manifiestas huellas de haber sufrido procesos de meteorización y erosión, actualmente inclinada y localizada sobre la ladera de los bloques pampeanos alabeada por fallas subverticales y generalmente inversas, en la vertiente opuesta. La figura 6 muestra el desarrollo de la penillanura en las Sierras Nordpampeanas y los esquemas de esfuerzos compresivos y extensivos determinados por Urreiztieta et al. (1993).

Durante la etapa de inversión tectónica se advierte un plegamiento suave de esta superficie como resultado de los esfuerzos superficiales vigentes en ese estadio. Esta superficie presenta distintos grados de retrabajamiento que dependen mayormente del lapso entre la exhumación y remoción de los sedimentos cenozoicos que la cubrían y el tiempo presente. En muchos casos cuando la remoción fue reciente se pueden observar rasgos decididamente geomórficos producidos por erosión fluvial o eólica. La penillanura está desarrollada sobre rocas metamórficas variadas, granitoides y milonitas derivadas de su deformación premesozoica. Los depósitos 


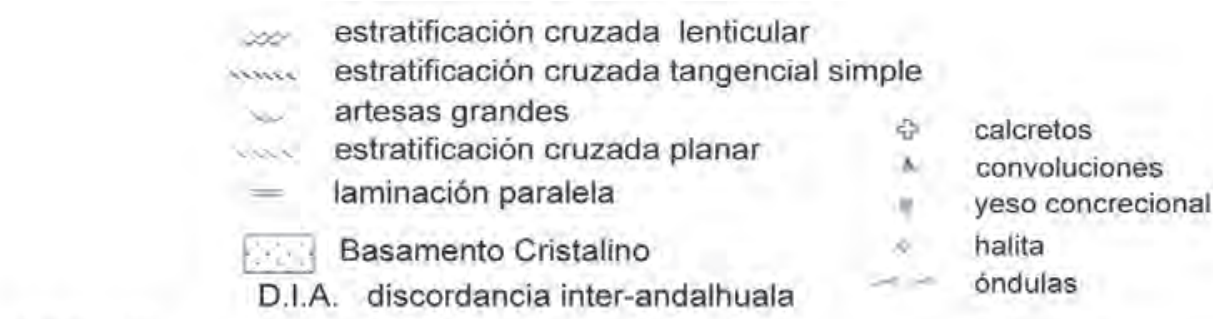

vertebrados gasterópodos

pelecipodos

trazas de vermes

pedotúbulos

rizoconcreciones

contacto erosivo

contacto plano

contacto ondulado

E2

Villavil

B

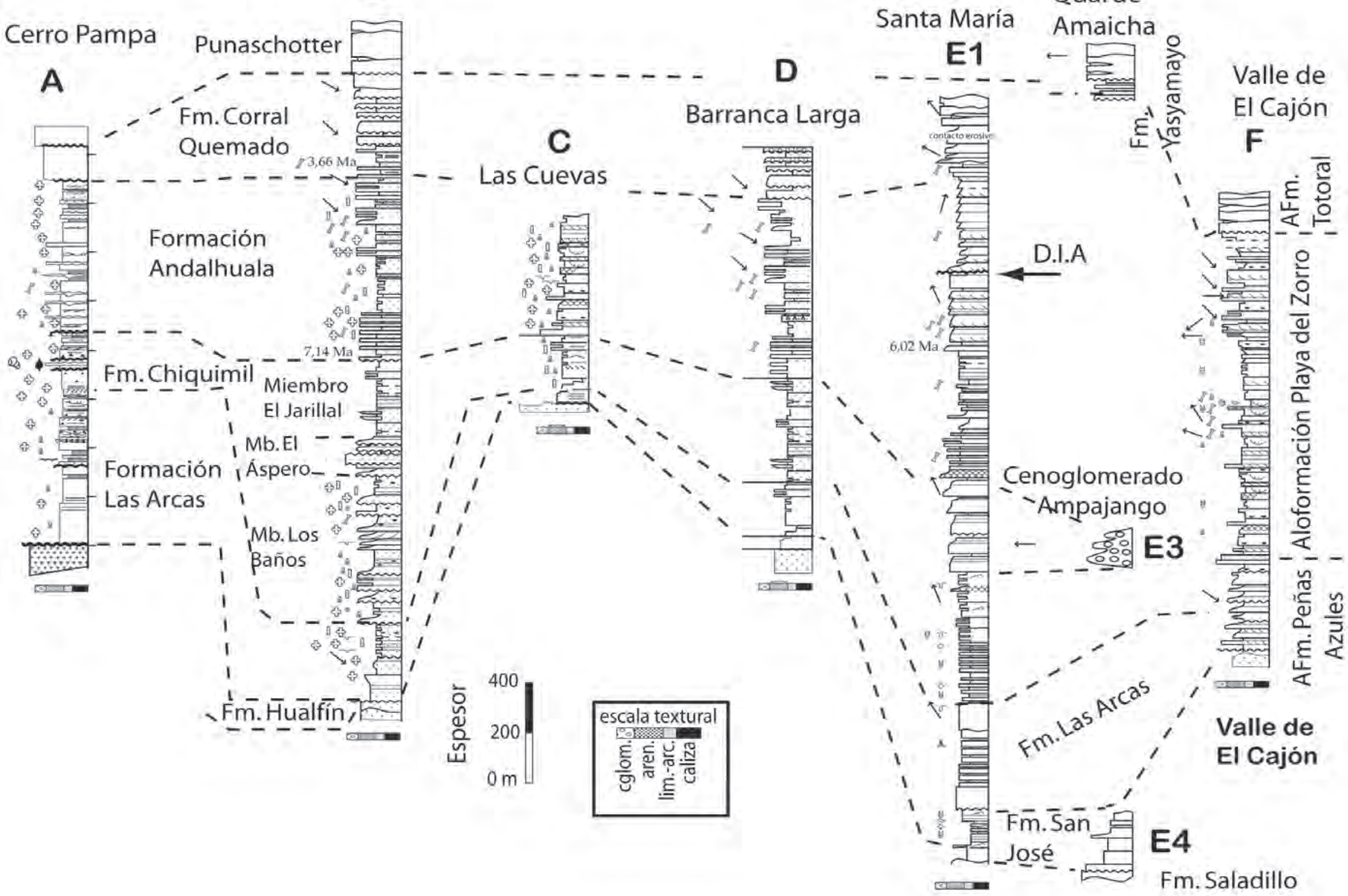

FIG. 3. Perfiles de detalle realizado en el sector sur de la Cuenca, en afloramientos continuos. 

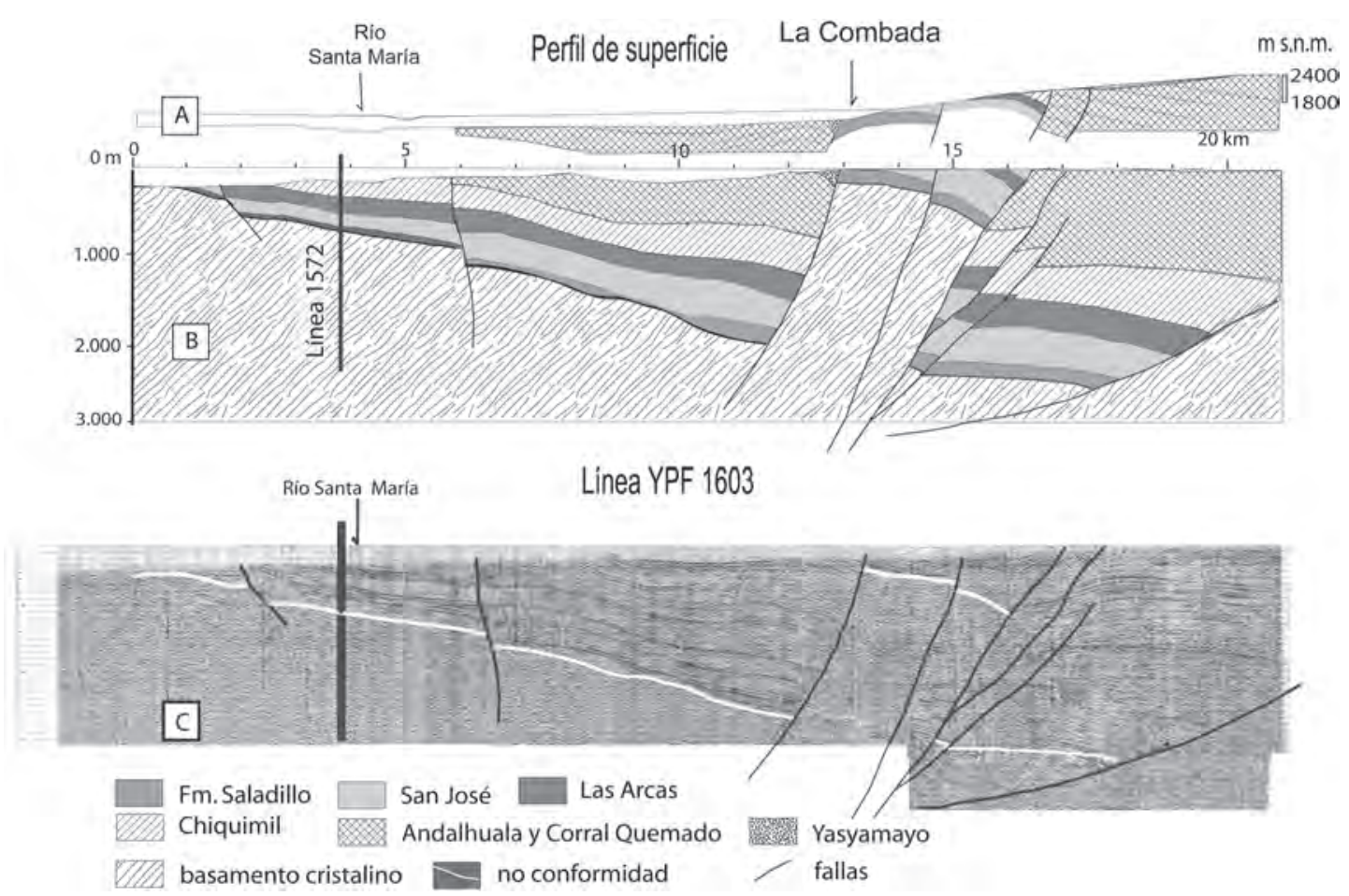

FIG. 4. La línea sísmica YPF 1603 y su interpretación de subsuelo ajustada con los espesores estratigráficos de los perfiles cercanos y el mapeo georreferenciado a escala 1:50.000 de la superficie, en la traza de la línea. Ver localización en la figura 1.

más antiguos que se apoyan sobre esta superficie peniplanizada se remontan al Pérmico y afloran cerca de la punta sur de la sierra de Ancasti en el paraje de La Dorada $\left(29^{\circ} 13^{\prime} 57^{\prime \prime} \mathrm{S}-65^{\circ} 29^{\prime} 35^{\prime \prime} \mathrm{O}\right)$ en la sierra Brava

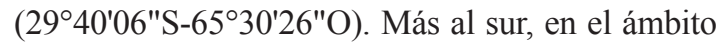
de la cuenca de Paganzo, la penillanura desaparece de manera que su constitución puede acotarse en el lapso Pérmico Superior-Triásico temprano a Paleógeno. Es muy probable que la duración e intensidad de los procesos de pedimentación fue diferente para los distintos sectores donde la penillanura está desarrollada. La influencia de la roca madre (granitoides, gneises, milonitas y esquistos) así como el proceso dominante: eólico (sierra del Cajón) o fluvial (sierras de Hualfín, Las Cuevas y cerro Pampa) son aspectos que determinan variaciones en el grado y tipo de desarrollo de esta superficie. La existencia de depósitos lacustres (Formación San José en el valle de Santa María) con varios niveles de foraminíferos bentónicos indica no sólo la conexión con la ingresión del mar paranaense (Mioceno medio, Gavriloff, 1999) sino también la altitud cercana al nivel del mar de la penillanura en el momento inicial de la sedimentación neógena en la cuenca (Gavriloff, 1999).
Las sedimentitas neógenas pueden presentar un reducido nivel basal gravoso-arenoso, producto de la remoción del basamento inmediato y moderadamente alterado (sierra de Hualfín, cerro Pampa) o materiales alóctonos (sierra del Cajón o Quilmes). Cuando las unidades atribuidas al paleógeno yacen sobre la penillanura (Formación Saladillo o Hualfín) el enrojecimiento del basamento y los niveles de alteración son mayores.

Por último, es oportuno un comentario sobre la extensión de la superficie de erosión que postulan Sobel y Strecker (2003). La penillanura pampeana por nosotros postulada no está presente sobre las Cumbres Calchaquíes y tampoco sobre la sierra de Aconquija (ver la figura 6), que integran el borde de la Cuenca de Santa María-Hualfín y el denominado 'Macizo Tucumano' (Bossi et al., 1984). Sobel y Strecker (2003) sostienen que existió una superficie de erosión (que según sus esquemas, ver su figura 13, es el fondo plano de la cuenca Neógena) desarrollada sobre las laderas orientales de ambas elevaciones que fue cubierta por una importante cubierta neógena (entre $1.000 \mathrm{a} 1.600 \mathrm{~m}$ ); todo esto basado en resultados de dos transectas donde se han 
medido trazas de fisión en apatita y un modelo de enfriamiento térmico aplicable a los últimos $14 \mathrm{Ma} \mathrm{y}$ cuya aplicación es incierta. La superficie de erosión en las Cumbres Calchaquíes, según Sobel y Strecker (2003), queda evidenciada por el perfil relativamente suave del faldeo oriental de esta elevación. Como prueba de su aspecto primitivo se ofrece la vista de la penillanura pampeana del extremo norte de la sierra de la Aconquija en la quebrada de Amaicha. Este bloque ubicado en la punta norte de la sierra presenta su penillanura inclinada al NE (fotografía de la figura 4a en Sobel y Strecker, 2003) y está cubierta por $1.100 \mathrm{~m}$ de sedimentos cenozoicos y originalmente formaba parte del piso de la cuenca (Bossi et al., 1984). Existen varios elementos de juicio que indican la presencia de estas sierras sobreelevadas con un relieve modesto durante el Cenozoico: (1) Las Cumbres Calchaquíes y la sierra de la Aconquija presentan fuertes diferencias petrológicas y están separadas geográficamente por la quebrada de Amaicha, por la cual corre un lineamiento tectónico con rumbo SSE-NNO, que estuvo activo desde el inicio de la sedimentación del Grupo Santa María, conformando un paleovalle con cabeceras en el cerro Muñoz, frente a Tafí del Valle; (2) Cerca de las cabeceras de este paleovalle aflora un importante espesor de conglomerados pertenecientes a las formaciones Andalhuala y Corral Quemado, de composición volcánica predominante, que provienen de un lugar cercano al Portezuelo de Las Ánimas, donde existía un centro volcánico de relieve considerable (Bossi et al., 1984), apoyado directamente sobre los gneises que forman el basamento de la sierra de Aconquija. La sucesión composicional de estos conglomerados sigue la ley del destape, siendo los inferiores, dentro de la Formación Andalhuala, totalmente volcánicos, lo que demuestra un progresivo ascenso de la sierra del Aconquija desde los tiempos de sedimentación de la Formación Andalhuala. Si el paleovalle Amaicha se hubiese formado a partir de los $5 \mathrm{Ma}$, la composición y textura de sus sedimentos axiales estaría controlada por la remoción de una muy abundante cubierta sedimentaria relativamente fina y de escasa litificación y no por un aparato volcánico inactivo desde mucho tiempo antes. Considerando los colores típicos de los sedimentos del 'ciclo Calchaquense' (verdes y rojos vivos) la sucesión sedimentaria del paleovalle debería mostrar un diseño parecido al Grupo Santa María, pero invertido, lo que no es el caso. (3) Las Formaciones Corral
Quemado y Yasyamayo (ambas conglomerádicas) que afloran a lo largo de la quebrada de Amaicha contienen cuerpos sedimentarios provenientes de ambos faldeos (cumbres Calchaquíes y Aconquija) de textura más gruesa, asociados a los depósitos conglomerádicos axiales. (4) Las paleocorrientes medidas en el Neógeno del valle de Santa María indican transporte desde el S-SSE. Las paleocorrientes en el valle del Cajón están dirigidas al este en las secciones basales y viran hacia el SE, en las superiores, que han sido relacionadas con los cambios de drenaje ocurridos por la elevación de la sierra de Quilmes, durante el Plioceno. (5) El gran espesor de depósitos conglomerádicos gruesos de la Formación Corral Quemado desde Ampajango hasta El Tesoro son facies de pie de monte (en el lugar que según la foto de la figura $4 \mathrm{c}$ de Sobel y Strecker, 2003, se inicia una transecta). Según Sobel y Strecker (2003) estos conglomerados son el resultado de la exhumación de la sierra de la Aconquija a los $5 \mathrm{Ma}$. Estos conglomerados disminuyen su participación hacia el norte e interdigitan profundamente con los términos superiores de la Formación Andalhuala, de manera que su edad es sin dudas mayor que la fecha de levantamiento propuesta. Recién después de la discordancia intra Andalhuala, la sedimentación es decididamente granocreciente. (6) La ladera oriental de la sierra de Aconquija que mira al valle de Tafí, no tiene penillanura, ni hay sedimentos neógenos en el fondo de este valle. (7) La quebrada de Amaicha contiene depósitos neógenos mayormente conglomerádicos que rellenaban un paleovalle que tenía sus nacientes en los gneises y volcanitas que afloran en la ladera oriental del Aconquija (Bossi et al., 1984). (8) La Formación Yasyamayo, que aflora en la quebrada de Amaicha y se expande lateralmente al ingresar al valle de Santa María, contiene materiales psefíticos gruesos, que provienen del basamento de las Cumbres Calchaquíes (filitas bandeadas) y del Aconquija (gneises) además de rodados volcánicos reciclados (Bossi et al., 1984). (9) El Cenoglomerado Ampajango formaba un abanico aluvial apoyado sobre un sector marginal de la cuenca y proviene de la destrucción de un aparato volcánico cercano, ubicado al este (cerro Las Ánimas, sierra de Aconquija). (10) El perfil estructural incluido por Sobel y Strecker (2003) similar al de González (2000), con el cual no concordamos en absoluto, tiene una particularidad: existe un macizo central elevado por fallas inversas que mantean hacia adentro. Si 
se postula una cuenca controlada por fallamiento inverso y rocas cenozoicas sobrecorridas a ambos lados, este bloque central debió tener una larga historia de elevación como elemento positivo. (11) El pasaje entre el Macizo Tucumano y los bloques inclinados al este (con penillanura y remanentes de Neógeno) ubicados al sur de Las Estancias (2729'39"S, 6601'24"O) es neto (Fig. 6). (12) Es imposible saber el espesor de basamento removido desde el inicio de la inversión tectónica (ca. $5 \mathrm{Ma}$ ) en la sierra de Aconquija y por ende del espesor de la supuesta cubierta sedimentaria. (13) Finalmente, una pregunta sin respuesta, si la cubierta sedimentaria se extendía indefinidamente sobre las sierras de Aconquija y Cumbres Calchaquíes, hacia los llanos orientales ¿de dónde provenía el material clástico grueso acumulado en varias unidades junto al borde este de la cuenca?

\subsection{La Cubierta Cenozoica}

Con criterio regional, González Bonorino (1950a) reconoció dos divisiones fundamentales en el Neógeno comprendido por la actual Hoja Belén (SEGEMAR ${ }^{1}, 1: 250.000$, cuyos extremos son: $27^{\circ} \mathrm{S}-67^{\circ} 30^{\prime} \mathrm{O}, 27^{\circ} \mathrm{S}-66^{\circ} \mathrm{O}, 28^{\circ} \mathrm{S}-66^{\circ} \mathrm{O}, 28^{\circ} \mathrm{S}-$ $67^{\circ} 30^{\prime} \mathrm{O}$, con colaboración de los autores, en prensa). 1) Calchaquense, unidad inferior texturalmente más fina y varicolor y 2) Araucanense, o unidad superior de areniscas y conglomerados pardos y grises con niveles de tefras blancas. Esta división persistió por muchos años y fue crucial en los estudios geológicos de las Sierras Pampeanas. Sin embargo, los términos Calchaquense o Calchaquí utilizados como unidades litoestratigráficas no se ajustan a las indicaciones del Comité Argentino de Estratigrafía $\mathrm{y}$ en consecuencia no resultan convenientes. El cuadro estratigráfico de la figura 2, que resume la estratigrafía de la región estudiada, puede servir de guía al lector por las relaciones de la nomenclatura con las relaciones cronológicas y espaciales.

\subsubsection{Formación Hualfín}

La Formación Hualfín ha sido propuesta por Muruaga (1998, 2001a, b) y Bossi et al. (1999), indicando como localidad tipo los afloramientos de las márgenes del río Villavil entre las localidades de Villavil y Hualfín, donde aflora con un espesor de 130 m. En el río Las Lajas alcanza su máximo espesor (492 m).
La Formación Hualfín aflora en forma continua en la ladera occidental de las sierras de Hualfín y Las Cuevas cubriendo periclinalmente el extremo sur de esta última (Fig. 5). La unidad yace en no conformidad sobre el basamento cristalino y a su vez es cubierta en disconformidad o discordancia angular por la Formación Las Arcas (Figs. 7A y 7B). La participación volcánica es reducida. Sin embargo, en las juntas de los ríos Jaciyae y Vis Vis (al sur del Complejo Farallón Negro) aparece atravesada por cuerpos volcánicos andesíticos irregulares en gran parte alterados.

Capas rojas equivalentes afloran en varios asomos menores en las sierras de Zapata y Vinquis (González Bonorino, 1950a), que fueron agrupadas por Sosic (1972) en la Formación Río Colorado.

Consiste en areniscas rojo ladrillo oscuro a violáceo, finas y medias, estratificadas en capas de 1 a $2 \mathrm{~m}$, macizas, de base plana, con laminación paralela, inclinada, bien cementadas o con cementación en forma de bochas. La sección inferior de la unidad presenta rodados dispersos y algunas intercalaciones de areniscas conglomerádicas con guijas y sábulo de granitoides, metamorfitas y pocas volcanitas intermedias. El nivel de diagénesis y litificación es elevado, aunque variable con una cementación carbonática o silícea importante. El color rojo es más intenso y oscuro que en la Formación Las Arcas (Muruaga, 1998, 2001b).

La fracción arcilla es una asociación illita de buena cristalinidad, caolinita y clorita con escasa participación de minerales del grupo esmectita, salvo en la parte superior donde domina esmectita, asociada a illita de baja cristalinidad.

Las paleocorrientes medidas (Muruaga, 1998) indican una dirección media de transporte hacia el este.

En la sierra de Hualfín, la unidad yace sobre la penillanura labrada en granito, y está afectada por fallas normales que estuvieron activas durante su acumulación (Fig. 5). Al norte de los Baños de Los Nacimientos, se advierte el desarrollo de discordancias progresivas dentro de las capas inferiores de la Formación Hualfín en las vecindades de los saltos de falla (Fig. 7B).

Se considera posible que esta unidad sea equivalente a la Formación Saladillo en el valle de Santa María sobre la base de correlaciones regionales auxiliadas con las líneas sísmicas del Campo del Arenal y valle de Santa María donde el contacto

${ }^{1}$ Hoja Belén, a escala 1:250.000 (en elaboración). SEGEMAR, Carta Geológica Económica de la República Argentina. Buenos Aires. 


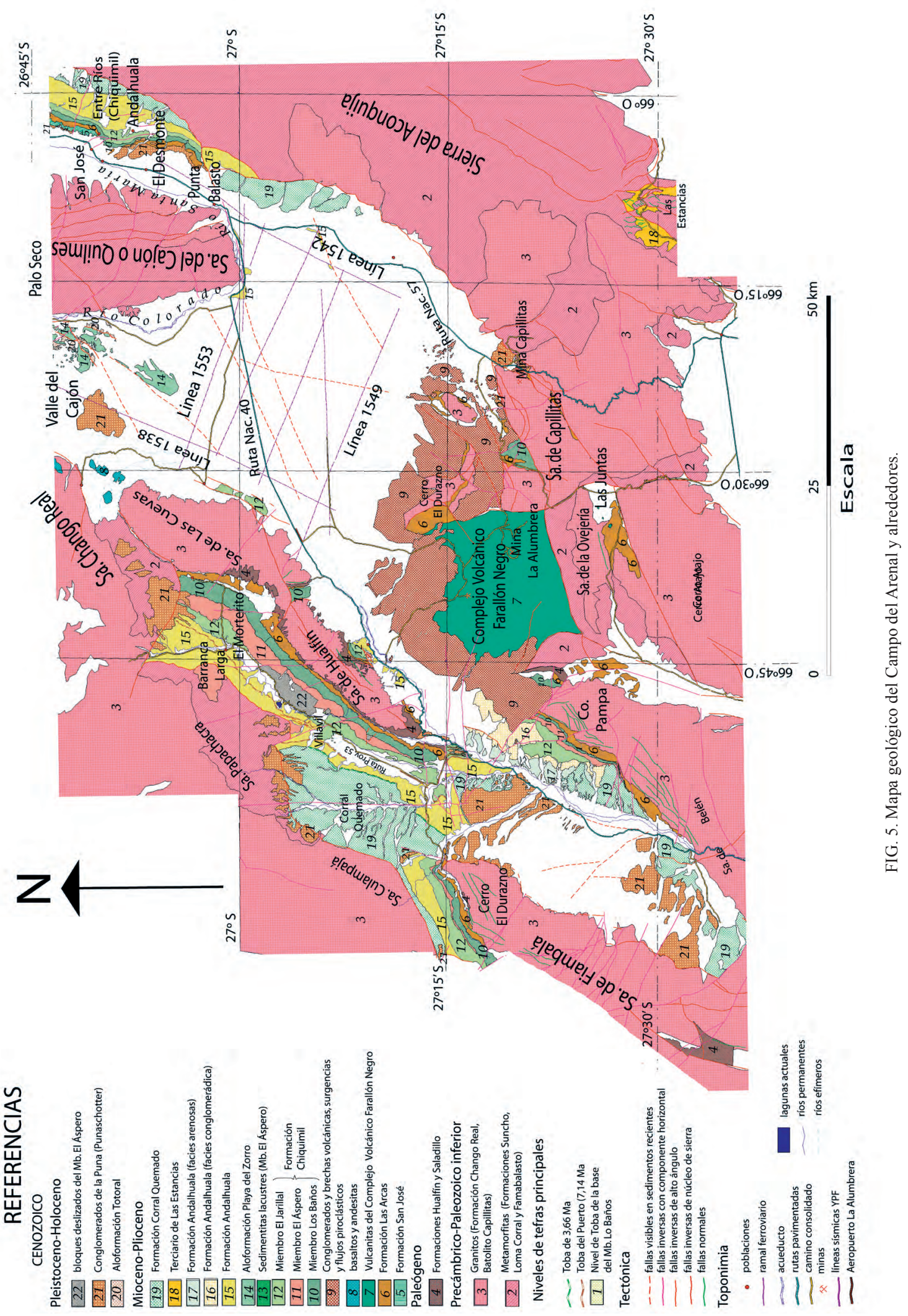


entre ambas unidades está definido por un marcado contraste de impedancia que definen dos planos reflectores muy intensos y continuos. La Formación Saladillo se encuentra ubicada en disconformidad debajo de la Formación San José en la quebrada de Amaicha. En la sección inferior de esta unidad, Nasif et al. (1997) exhumaron restos de mamíferos a los que asignan edad Friasense (edad incierta cercana a 15 Ma in Flynn y Swisher, 1995). La Formación Saladillo continúa hacia el norte debajo de las capas neógenas y reaparece encima de la Formación Yacomisqui (al sur del cerro Chimpa), integrando el Subgrupo Santa Bárbara en la Yesera (al este de Cafayate en la quebrada de Las Conchas, Salta). Los niveles pelíticos rojos correspondientes a esta unidad están intruidos por un dique basáltico fechado mediante K-Ar en $52 \pm 10$ Ma (Linares y González, 1990). La edad de la Formación Saldillo queda así comprendida entre el Mioceno temprano y el Paleoceno.

La Formación Hualfín no ha brindado restos fósiles hasta el presente ni tiene dataciones radiométricas y su edad es incierta. La relación de yacencia y similitud litológica con la Formación Saladillo, nos permite ubicarla tentativamente en el Paleógeno. Recientemente Rosello et al. (1999) presentaron la datación de una colada basáltica (131 $\pm 4 \mathrm{Ma}, \mathrm{K}-\mathrm{Ar}$ sobre roca total) incluida en capas rojas que afloran en la Puerta de San José (sierra de Belén). Lamentablemente para la cuestión de edad se trata de dos coladas basálticas con una fuerte alteración de la pasta y fenocristales, inadecuada para este tipo de datación. Por otra parte, las capas rojas asociadas a estas coladas pertenecen a la Formación Las Arcas y probablemente sean de edad Miocena.

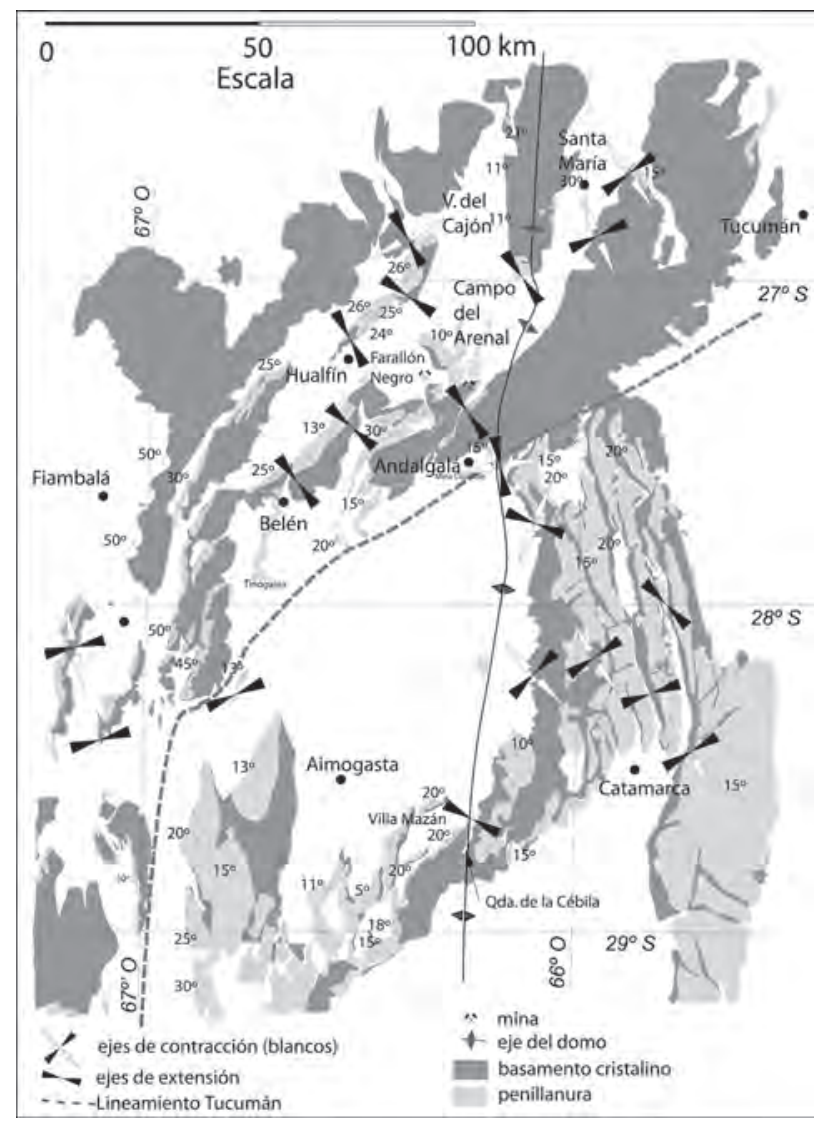

FIG. 6. Mapa general de la penillanura pampeana con las inclinaciones de los bloques que contienen sus varios fragmentos y esquema de esfuerzos medidos en estructuras del basamento por Urreiztieta et al. (1993). Posiciones del Lineamiento Tucumán y del eje del domo pampeano. 


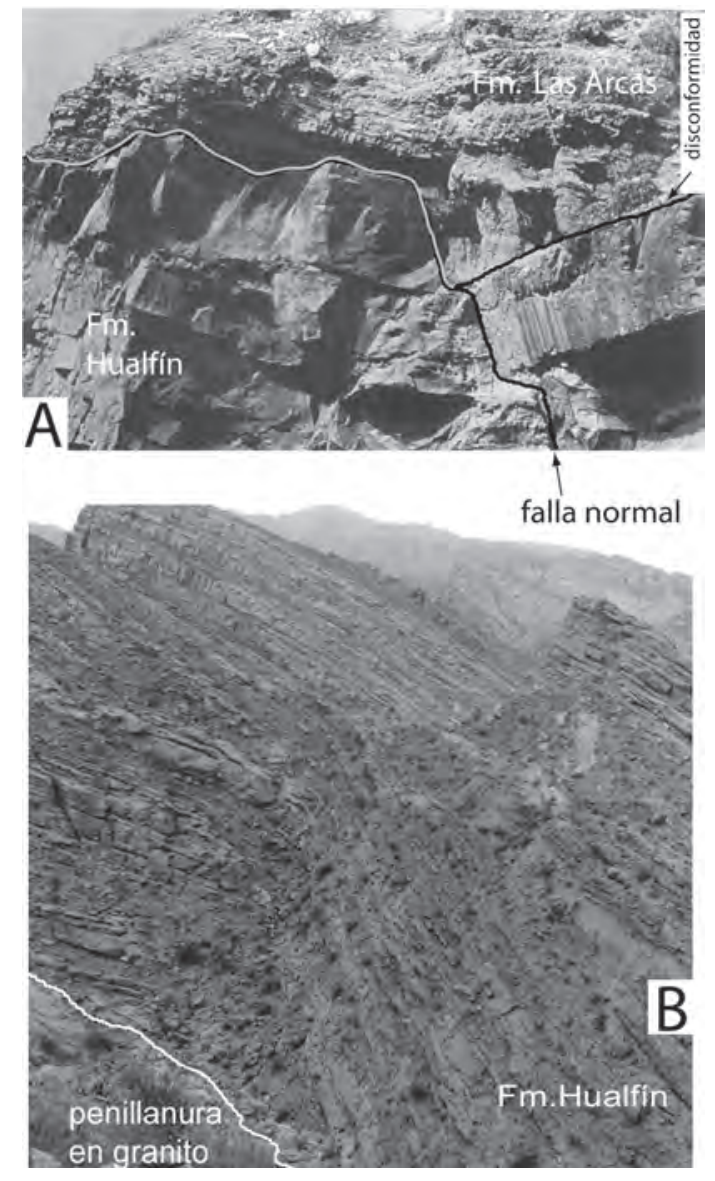

FIG. 7. A. Fotografía mirando al SE de las capas rojas de la Formación Hualfín y Las Arcas en el río Villavil que muestra la disconformidad entre ambas unidades y la presencia de una falla normal plana que afecta solamente la Formación Hualfín; B. La Formación Hualfín sobre la penillanura labrada en el granito de la sierra de Hualfín. Se observa aquí la posición de las capas que forman discordancias progresivas asociadas a la actividad de fallas normales planas.

\subsubsection{Grupo Santa María}

El Grupo Santa María fue propuesto por Galván y Ruiz Huidobro (1965) y tiene su área tipo en el valle de Santa María. La correlación regional entre el valle de Santa María y el área de Villavil-Corral Quemado fue revisada y definida en el trabajo de Bossi et al. (1987), reafirmando, al publicarse, las ideas de Stahlecker (Marshall y Patterson, 1981). El grupo, con su integración modificada por Bossi y Palma (1982), está constituido por las formaciones: San José (inferior), Las Arcas, Chiquimil, Andalhuala y Yasyamayo (superior). La Formación
Saladillo, originalmente incluida en el Grupo, fue excluida por su relación de disconformidad o discordancia angular debajo de la Formación San José y su posible edad paleógena (Bossi y Palma, 1982; y en trabajos posteriores Bossi et al., 1987, 1993, 1994, 1997 y 1999). Asimismo fueron desacreditadas las 'Hiladas' de Zanja del Molle y Los Corrales (Peirano, 1945, 1956) definidas exclusivamente para la quebrada de Amaicha (Bossi et al., 1984). Bossi (1969) agregó al grupo el Cenoglomerado Ampajango estudiado por Bensel (1986) y publicado en Bossi et al. $(1993,1994)$ que aflora en el faldeo occidental de la sierra del Aconquija en el río homónimo (Figs. 1 y 3). El Cenoglomerado tiene un espesor máximo de $50 \mathrm{~m}$ y yace sobre $2 \mathrm{~m}$ de capas rojas silicificadas atribuidas a la Formación Saladillo y éste, a su vez, sobre el Basamento Cristalino. Puede ser correlacionado con el Miembro A de la Formación Chiquimil, que aflora en la parte baja del valle. Se trata de depósitos psefíticos matriz soportante, de composición exclusivamente volcánica que constituyen remanentes de los depósitos de pie de monte generados a partir del aparato volcánico ubicado en el cerro Las Ánimas (sierra de Aconquija) que constituyó un relieve importante durante el Mioceno superior.

Históricamente las unidades pertenecientes al Grupo fueron asignadas a varios 'pisos' estratigráficos: Calchaquense, Araucanense (o Araucano), Santamariano y Famatino, divisiones que aún se mencionan en la literatura y que son obsoletas. Bondendender(1911) introdujo el término Calchaquense para ciertos horizontes rojos y grises verdosos en la Provincia de La Rioja que consideró poscretácicos. A su vez, Groeber (1929) propuso la edad miocena superior para las capas con Corbícula del valle de Santa María que se encuentran en la Formación San José. Frenguelli (1930) estableció una división en Santamariano (inferior) y Araucaniano (superior) separados por una discordancia. El Santamariano fue dividido en tres: Famatino inferior, Famatino superior y Calchaquí. Es posible que la Formación Las Arcas sea equivalente a esta última unidad.

En tiempos recientes, se han realizado precisiones en la correlación regional que involucran la región Hualfín-Las Cuevas (Muruaga, 1998) y el cerro Pampa (Bossi et al., 1999), además de relevamientos regionales para la Hoja Belén (1:250.000 del SEGEMAR, siendo sus límites: $27^{\circ} \mathrm{S}-67^{\circ} 30^{\prime} \mathrm{O}, 27^{\circ} \mathrm{S}-$ $\left.66^{\circ} \mathrm{O}, 28^{\circ} \mathrm{S}-66^{\circ} \mathrm{O}, 28^{\circ} \mathrm{S}-67^{\circ} 30^{\prime} \mathrm{O}\right)$ que extienden la presencia del Grupo más allá del valle de Santa 
María. Las curvas de variación de los isótopos ambientales $\delta^{13} \mathrm{C}$ (PDB o/oo) y $\delta^{18} \mathrm{O}$ (PDB o/oo), a partir de calcretos y rizoconcreciones colectadas de los perfiles del cerro Pampa y El Cajón (Muruaga et al., 2003) y de Villavil (Latorre et al., 1997) son llamativamente concordantes. La relación es menor con las curvas publicadas para el valle de Santa María (Kleinert y Strecker, 2001) debido a que estas últimas pertenecen a perfiles unidos sin continuidad estratigráfica segura. Los datos de isótopos ambientales han permitido ajustar la correlación regional y extrapolar fechados de tefras y de sedimentos asociados en la región considerada.

La denominación Formación Corral Quemado, cuya área tipo está en la localidad homónima al SO de la cuenca, fue utilizada en el valle de Santa María y quebrada de Amaicha por varios autores (Kraglievich, 1952; Simpson, 1974; Stahlecker in Marshall y Patterson, 1981; Bossi et al., 1987; Strecker, 1987 y Bossi et al., 1999) para referirse a los conglomerados cuspidales de la sucesión cenozoica y resulta una práctica razonable a escala regional avalada por similitudes en términos de estadio de evolución tectosedimentaria y principalmente edades.

En el área de la Hoja Belén (inmediata al sur de la zona estudiada) no se han descrito equivalentes de la Formación San José ni tampoco del Cenoglomerado Ampajango. En cuanto a la Formación Yasyamayo, puede ser en parte equivalente al Punaschotter y a la Secuencia III en el valle del Cajón (Bossi et al., 1993, 1994 y 2001).

El Grupo Santa María en conjunto puede correlacionarse con el Grupo El Bolsón definido por Turner (1973) en la Hoja Geológica 1:200.000 Laguna Blanca (cuyos extremos son: $26^{\circ} 30^{\prime} \mathrm{S}-67^{\circ} \mathrm{O}$, $26^{\circ} 30^{\prime} \mathrm{S}-66^{\circ} 15^{\prime} \mathrm{O}, 27^{\circ} \mathrm{S}-66^{\circ} 15^{\prime} \mathrm{O}, 27^{\circ} \mathrm{S}-67^{\circ} \mathrm{O}$ ), integrado por las Formaciones El Morterito, El Áspero y El Cajón y cuyo perfil tipo se encuentra en el faldeo occidental de la sierra de Las Cuevas a la altura del Puesto El Morterito. Existen varios argumentos de peso para abandonar esta nomenclatura:

1. Al definir el Grupo, Turner (1973) no tuvo en cuenta los aportes de Stahlecker publicados parcialmente por Riggs y Patterson (1939) y las fuertes relaciones estratigráficas y paleontológicas entre las regiones de Hualfín-Puerta de Corral Quemado y Chiquimil (hoy Entre Ríos) en el valle de Santa María.

2. La división en tres unidades entre las cuales se encuentra la Formación El Áspero (reducida en nuestro esquema a miembro; Muruaga, 1998, 2001a), es inaplicable al sur de Villavil, donde éste desaparece. Aunque los conglomerados volcánicos de composición predominantemente andesítica también se encuentran en el valle del Cajón, Turner (1962) no pudo reconocerlos como parte de esta unidad (en realidad lo expresa con dudas).

3. En el valle del Cajón (Fig. 1), Turner (1962, 1973) incluye toda la sucesión neógena dentro de la Formación El Morterito. Sin embargo, es evidente en los perfiles de detalle relevados que esta sucesión incluye estratos correspondientes a la Formación Las Arcas y el Miembro Los Baños (Muruaga, 1998, 2001a). Las dataciones radiométricas (Bossi et al., 2001), los vertebrados fósiles y la misma litología indican que se encuentran secciones estratigráficas equivalentes a todo el Grupo El Bolsón.

4. La nomenclatura geológica aplicada al valle de Santa María está fundada en una excelente correlación de edades y litologías, que se repite en forma clara en las dos regiones clásicas del Neógeno de la Cuenca de Santa María-Hualfín: Chiquimil y Hualfín-Puerta de Corral Quemado (Stahlecker in Marshall y Patterson, 1981 y Bossi et al., 1987) y es aplicable a toda la región considerada con la excepción del valle del Cajón. En este último valle, los elementos litoestratigráficos diagnósticos (colores, texturas y estratificación) del Grupo Santa María no son discernibles. Debido a esta causa y por la presencia de disconformidades prominentes, mapeables regionalmente, se consideró más adecuado realizar una división aloestratigráfica (Bossi et al., 1992, 2001 y figura 2).

\subsubsection{Formación Las Arcas. La Formación Las} Arcas (Muruaga, 1998), en la región considerada, está integrada por areniscas finas a medianas y pelitas subordinadas o en camadas de paraclastos con intercalaciones menores de conglomerados de rodados graníticos y metamórficos, generalmente friables color rojo naranja. Constituye la base del Grupo Santa María, en la Hoja Belén. La Formación San José únicamente aflora en el valle de Santa María (Fig. 2, perfil E1). Bossi et al. (1987) sobre la base de las dataciones radiométricas, los perfiles de detalles y las correlaciones de Stahlecker (in Marshall y Patterson, 1981), identificaron la unidad en el Campo del Arenal y región circundante. La unidad comprende la sección inferior de la 
sucesión Calchaquense (mapeada por González Bonorino, 1950a) y queda ubicada debajo de la línea montmorillonita (Bossi et al., 1987). La línea montmorillonita define el techo de la unidad y marca el ingreso de montmorillonita de alta cristalinidad de proveniencia volcánica y los colores amarillos. La sección superior del dicho Calchaquense es la Formación Chiquimil, que sigue encima.

En el cerro Durazno (oriental) sobre la sucesión de areniscas rojas y en marcada discontinuidad siguen las brechas volcánicas y brechas 'ash-block' intruidas por andesitas del Complejo Volcánico Farallón Negro. Una relación estratigráfica similar se verifica en las cercanías de la mina Capillitas, Puesto Casadero y cerro El Atajo, en los alrededores de este gran centro volcánico (Figs. 1 y 5).

Los afloramientos son continuos en la ladera occidental de la sierra de Hualfín, mientras que en la ladera oriental y en la sierra de Las Cuevas aparece saltuariamente (Los Baños de los Nacimientos y Las Cuevas). En el cerro El Durazno (occidental), la Formación Las Arcas aflora en una faja continua de aproximadamente $10 \mathrm{~km}$ de extensión en los márgenes norte de los ríos Tolar y El Durazno (cerca de 27 en la figura 1).

La composición de la fracción arcilla (Muruaga, 1998) de la Formación Las Arcas es una asociación de illita de baja cristalinidad y montmorillonita con abundante calcita y escaso cuarzo como accesorios, provenientes principalmente de la alteración del Basamento Cristalino.

El perfil de Villavil (Muruaga, 1998) ubicado en el faldeo occidental de la sierra de Hualfín puede considerarse tipo para la región (Fig. 3B). Tanto en el perfil del cerro El Durazno (occidental) como el de la sierra de Las Cuevas (Fig. 3C, Barranca Larga; Muruaga,1998, 2001b; J.G. Sanagua, comunicación personal, 1997), la unidad se manifiesta con una notable carencia de conglomerados, predominando las areniscas finas y medianas macizas, pardo rojizas, con rodados dispersos y paraclastos pelíticos, que alternan con niveles de pelitas y areniscas finas ocasionalmente bioturbadas, moteadas y con pedotúbulos. Sólo en la parte superior aparecen algunos conglomerados con guijas redondeadas, en capas lenticulares delgadas (65\% gneises y cuarzo, $5 \%$ de esquistos y $30 \%$ de volcanitas).

La unidad yace en disconformidad sobre la Formación Hualfín y cuando ésta falta, en no conformidad sobre la Penillanura Pampeana. El pasaje hacia la Formación Chiquimil es transicional y está defi- nido por un cambio de color de rojo naranja a pardo amarillento; además, las texturas dominantes en las areniscas pasan de finas a medianas y gruesas.

La unidad es anterior a la irrupción del volcanismo calcoalcalino (Muruaga, 1998) del Complejo de Farallón Negro, cuya edad máxima se estima en 12 Ma (Stipanicic y Linares, 1975) y en consecuencia puede tener una edad inferior a esa datación. Se han encontrado escasos fósiles, entre ellos ostrácodos y pelecípodos de agua dulce (Muruaga, 1998) en la sierra de Hualfín y pisadas de Charadriformes (Segovia, 2004) en el cerro Pampa. En el valle de Santa María, se ha recolectado un mamífero asignado al Chasicoense o Friasense (Nasif et al., 1997) en las capas rojas que constituyen la base de la Formación San José en la quebrada de Amaicha.

La datación en 9,14 $\pm 0,02$ Ma de Sasso (1997) para un cuerpo subvolcánico intruido en el Miembro El Áspero de la Formación Chiquimil (cerca de Villavil), que yace por encima y la naturaleza prevolcánica de la unidad, nos ubica en un tiempo anterior a $12 \mathrm{Ma}$, que es el inicio del volcanismo de Farallón Negro (Aguas de Dionisio), siendo ésta la edad mínima (Mioceno Medio) para la Formación Las Arcas.

Las formaciones Hualfín y Las Arcas pueden ser diferenciadas en el campo, sólo cuando están juntas. El límite entre las dos unidades se reconoce por la presencia de una discordancia angular entre $4^{\circ}$ a $8^{\circ}$ y una suave variación en el rumbo de las capas (e.g., extremo austral de la sierra de Hualfín, en el río Aguas Calientes y en la unión de los ríos Yaciyae, Vis Vis y Las Lajas, ver figuras 1 y 5).

La Formación Las Arcas fue acumulada en una gran planicie poblada de barreales (algunos bañados o lagunas semipermanentes) y cursos de agua que discurrían por un fondo de cuenca plano de muy escasa pendiente y con un relieve del área fuente bajo o muy lejano (la primera posibilidad parece más adecuada; Muruaga, 1998, 2001b). Posiblemente el clima era cálido y húmedo en la estación estival y seco en el invierno, como posible explicación para su elevado contenido en pigmento de óxido férrico (Muruaga, 1998). Parte del color rojo de la unidad puede derivar de la erosión parcial de la subyacente Formación Hualfín.

2.2.2.2 Formación Chiquimil. El término Formación Chiquimil fue introducido por Bossi y Palma (1982) sobre la base de una reconsideración y valorización de los estudios estratigráficos llevados a 
cabo por Stahlecker en 1926 (in Riggs y Patterson, 1939; Marshall y Patterson, 1981). La unidad se la reconoce fácilmente en el campo por el marcado color amarillo de sus areniscas, aspecto que usó Stahlecker para correlacionar las capas equivalentes entre Chiquimil (hoy Entre Ríos, valle de Santa María) y Hualfín-Puerta de Corral Quemado, al NE y SO del Campo del Arenal, respectivamente. Consiste en areniscas finas en estratos tabulares continuos con estratificación cruzada tabular tangencial simple alternando con pelitas macizas y laminadas que aparecen como paraclastos en muchas areniscas. Los conglomerados son infrecuentes y en capas lenticulares muy delgadas. Las pelitas contienen una rica fauna de vertebrados e impresiones y carbonizaciones de hojas y tallos. Se registran dos niveles de toba de $0,2 \mathrm{~m}$ cada uno.

Esta correlación está apoyada por las dataciones radiométricas realizadas y el contenido fosilífero. Es además destacable que la composición de los argilominerales presenta una eleva proporción de esmectitas de alta cristalinidad que no se repite en las unidades inferiores y superiores y una petrografía de las psefitas y psamitas dominada por materiales volcanoclásticos. La lista de fósiles reconocidos ha crecido considerablemente desde los tiempos de Riggs y Patterson (1939). Según Muruaga (1998, 2001a) la Formación Chiquimil, tal como aflora en los faldeos occidentales de las sierras de Hualfín y Las Cuevas, debe ser dividida en tres miembros: Los Baños (inferior), El Áspero y El Jarillal. Los miembros A y B de Stahlecker (in Marshall y Patterson, 1981) equivalen a los Miembros Los Baños y El Jarillal, respectivamente. Solamente en el área comprendida entre la Puerta de Corral Quemado, Villavil y Barranca Larga, aparecen separados por el Miembro El Áspero (Fig. 5)

Los afloramientos de esta unidad aparecen rodeando el núcleo central del Complejo Volcánico Farallón Negro, entre el cerro del Durazno (oriental), La sierra de Capillitas, Las Juntas, Mina Capillitas y Ampujacu. Los conglomerados y brechas volcánicas acompañados por intrusivos constituyen la base y en ocasiones la totalidad de la Formación Chiquimil.

Según Muruaga (1998) la Formación Chiquimil tiene un espesor de $1.392 \mathrm{~m}$ en el perfil de Villavil y de 1.129 m en el perfil cerro El Durazno (occidental). El espesor disminuye rápidamente hacia el río Las Cuevas $(800 \mathrm{~m})$ y hacia el $\mathrm{SE}$ en el cerro Pampa, donde se han medido $400 \mathrm{~m}$.
Los niveles de arcilitas lacustres del valle del Cajón con Neocorbicula stelzneri y gasterópodos pertenecen a la Secuencia II de Bossi et al. (1993) y equivalen litoestratigráficamente a la Formación Chiquimil. En la misma situación se encuentran los restos de mamíferos y aves mencionados por Riggs y Patterson (1939) en su horizonte Chiquimil B de la Región de Puerta de Corral Quemado y Peirano (1943) en los niveles equivalentes del valle del Cajón. Recientemente, Muruaga (1998) presentó una lista ampliada, sobre la base de numerosos hallazgos fósiles en el área de Villavil. La fauna ha sido ubicada en el Huayqueriense por Powell et al. (1998). La edad Huayqueriense de esta fauna está acotada en el intervalo 6,8-9 Ma (Flynn y Swisher, 1995) sugerido por radiometría, o sea Mioceno tardío temprano (Cowle y Basset, 1989).

En la sierra de Hualfín y cerro El Durazno (occidental), las capas de la Formación Chiquimil se apoyan en concordancia sobre la Formación Las Arcas.

Las paleocorrientes (Muruaga, 1998, 2001a) medidas en las areniscas de los miembros El Jarillal y Los Baños, presentan una gran media hacia el ESE, que difiere con la del Miembro El Áspero, cuya gran media es hacia el SE. En el Perfil del cerro Pampa, las paleocorrientes indican una proveniencia desde el basamento ubicado al este y sureste, que cerraba por allí la cuenca. Sin embargo, los niveles volcanoclásticos del Miembro El Áspero, en la sucesión del cerro Pampa, tienen paleocorrientes desde el norte y NNE, o sea directamente del gran volcán ubicado en el área de Farallón Negro. Este resultado implica una inversión de la dirección de drenaje para la sucesión del Miembro El Áspero, en esta zona. Las paleocorrientes de las unidades que siguen encima, indican que, inmediatamente después, fue restablecido el sistema fluvial con proveniencia del este y sudeste (Miembro El Jarillal y formaciones Andalhuala y Corral Quemado).

Los extrusivos dominantes en el Complejo Volcánico Farallón Negro están constituidos principalmente por brechas volcánicas andesíticas (Sasso, 1997). Según Proffett (1994, 1995), existen cinco unidades estratigráficas en las inmediaciones de Bajo de la Alumbrera, con un espesor total de $500 \mathrm{~m}$. El fechado de mayor edad en este complejo es de 12,6 Ma (Sasso, 1997) coincidente con los datos de Linares y González (1990).

Muruaga (1998) asignó el Miembro Los Baños al Mioceno superior de acuerdo a la escala de Cowle 
y Basset (1989), sobre la base de la datación de 9,14 $\pm 0,09 \mathrm{Ma}$ (Sasso, 1997) de la colada andesítica intercalada en el sobreyacente Miembro El Áspero. La unidad es correlacionable con la Aloformación Playa del Zorro (Secuencia II, Bossi et al., 1992, 1993, 1999, 2001) en el valle de El Cajón y a la Formación Chiquimil y Cenoglomerado Ampajango en el valle de Santa María (Bossi et al., 1987, 1993).

Butler et al. (1984) estimaron una edad para el límite entre las formaciones Chiquimil y Andalhuala en 7,5 Ma basándose en magnetoestratigrafía y dataciones radiométricas de la tefra del Puerto (paraje al norte de Puerta de Corral Quemado) datada por Marshall et al. (1979) en 6,68 $\pm 0,02 \mathrm{Ma}(\mathrm{K}-\mathrm{Ar}$ ) y por Latorre et al. (1997) en 7,14 $\pm 0,02 \mathrm{Ma}(\mathrm{Ar} / \mathrm{Ar})$.

La litología de la porción inferior del Miembro Los Baños, constituida por la alternancia de areniscas medianas a gruesas alternando con pelitas y conglomerados volcanoclásticos, indica un ambiente fluvial dellanura, posiblemente bajo clima con estación estival húmeda, suelos tipo vertisoles y fuerte oscilación del nivel freático y canales enlazados efímeros.

Los conglomerados y brechas volcanoclásticas de la sección media (Miembro El Áspero) implican el arrastre de materiales psefíticos de relieves cercanos e importantes, con un predominio de procesos de remoción en masa: brechas 'ash-block', brechas volcánicas ('lahares') y erupciones explosivas. Este cambio de roca madre está asociado al crecimiento de relieves volcánicos en varios puntos vecinos a la cuenca, en el borde oeste (Puna Austral), en sectores intracuencales (Farallón Negro) y borde oriental (cerro Las Ánimas).

Con la atenuación del volcanismo y su total desaparición en áreas cercanas a la cuenca, la sedimentación se vuelve predominantemente arenosa, de composición metamórfica-granítica, con presencia volcanoclástica decreciente (Miembro El Jarillal de la Formación Chiquimil). Muruaga (1998) infiere un paleoambiente de ríos permanentes de baja sinuosidad constituyendo un sistema fluvial entrelazado gravoso con frecuentes depósitos de explayamiento, flujos mantiformes y fango preservados escasamente que conformaban la planicie de inundación. En el perfil El Durazno, Muruaga (1998) identifica facies de abanicos aluviales, provenientes del borde oeste.

2.2.2.3 Formación Andalhuala. La Formación Andalhuala comprende el Araucaniano medio e inferior de Frenguelli (1930) y el horizonte Arau- canense de Riggs y Patterson (1939), la Formación Araucanense de Butler et al. (1984) y parte de la Formación El Cajón (Turner, 1962).

La introducción de la Formación Andalhuala (Andalhualá en Kraglievich, 1934), proveniente del valle de Santa María, en esta parte de la Cuenca, fue sugerida por Bossi et al. (1987, 1993, 1999) y Muruaga (1998). La denominación Formación Andalhuala es preferida a la de Formación El Cajón (Turner, 1973), por los motivos que ya fueron expresados, en referencia al Grupo El Bolsón.

La Formación Andalhuala aflora extensamente y con espesores importantes en el área de HualfínPuerta de Corral Quemado, disminuyendo sensiblemente de espesor hacia el sur por el faldeo occidental del cerro El Durazno (occidental) donde sigue como una faja continua de afloramientos hasta el río las Lajas en el faldeo occidental de la sierra de Zapata (Figs. 1 y 5). Ocurre también, con gran desarrollo en el faldeo occidental del cerro Pampa, hasta la Puerta de San José en la sierra de Belén. También aflora al norte del cerro Pampa y se manifiesta saltuariamente a ambos lados del río Los Nacimientos entre Farallón Negro y la sierra de Hualfín y entre ésta y la sierra de Las Cuevas. La unidad continúa hacia el este y norte, aunque está prácticamente ausente en el subsuelo del Campo del Arenal, reaparece al norte, cerca de la sierra de Quilmes y en facies casi totalmente conglomerádicas en el faldeo occidental de la sierra del Aconquija. En este último caso, se ha preferido mapear los afloramientos cenozoicos como Formación Corral Quemado.

En el cerro Pampa, Bossi et al. (1999) separaron la unidad en dos secciones: (a) conglomerádica fina con clastos subangulosos en la base y (b) una sección arenosa-limosa en la parte superior. El espesor total medido es de $633 \mathrm{~m}$.

El espesor máximo de la unidad alcanza los $904 \mathrm{~m}$ en el Perfil Villavil (F3B-11) (Muruaga, 1998) y disminuye progresivamente hacia el norte y sur. En el Perfil El Durazno es de 794 m y en el Perfil Río Las Lajas es de 200 m. En Barranca Larga el espesor es de $250 \mathrm{~m}$ (F3D-11). En el perfil de Puerta de Corral Quemado, Stahlecker (1926, in Marshall y Patterson, 1981 y Butler et al., 1984) definen el Araucanense con un espesor total de $475 \mathrm{~m}$. Sin embargo, la suma de espesores entre las secciones 15 y 28 del perfil de Stahlecker, que realmente corresponden a la Formación Andalhuala (según Bossi et al., 1987 y Muruaga , 1998) es de 730 m, cercana a los 830 m medidos por Bossi et al. (1987) y Muruaga 
(1998) para el intervalo estratigráfico entre las tefras de 6,68 Ma y la de 3,54 $\pm 0,03 \mathrm{Ma}$.

Riggs y Patterson (1939) correlacionaron la fauna encontrada con aquella de Huayquería (Mendoza), asignándole una edad pliocena. Cabrera (1944) y Simpson (1974), por su parte, concluyeron que las faunas de las formaciones Corral Quemado y Araucanense (hoy Formación Andalhuala) eran iguales y correspondía ubicarlas en el Huayqueriense.

Esta unidad es la más rica en vertebrados fósiles, con restos de aves, reptiles y mamíferos. Muchos de los mamíferos han producido polémicas de edad y varios intentos de definir dos edades mamíferos: Huayqueriense, con edad entre 6,8 y 9 Ma y Montehermosense, con edad entre 6,8 y $4 \mathrm{Ma}$ (Flynn y Swisher, 1995). En realidad, ambas faunas transgreden el límite tardío indicado. A partir de los 6,8 Ma, la fauna es híbrida, con elementos de edad Montehermosense asociados a otros relícticos de edad Huayqueriense (Bossi et al., 1998).

Mientras algunos autores ubican la unidad en el Plioceno sensu lato (González Bonorino, 1950b; Turner, 1962) otros indican una edad Mioceno tardío a Plioceno temprano, sobre la base del contenido fosilífero, edades radiométricas y magnetoestratigrafía del área de la Puerta de Corral Quemado (Bossi y Palma, 1982; Bossi et al., 1987; Marshall et al., 1979; Butler et al., 1984; Latorre et al., 1997 y escala de Cowle y Bassett, 1989).

El contacto con la subyacente Formación Chiquimil está definido por la 'línea amarilla' (Bossi et al., 1987). En el valle de Santa María, la Formación Andalhuala se apoya concordantemente sobre la Formación Chiquimil. La prominente 'tefra de El Puerto', que aflora junto al camino entre Villavil y Puerta de Corral Quemado, ha sido datada por Marshall et al. (1979) en 6,68 y por Latorre et al. (1997) en 7,14 Ma, y se encuentra ligeramente encima del contacto entre las Formaciones Chiquimil y Andalhuala.

La edad mínima del límite superior de la formación, en el área de Corral Quemado, está acotada por la tefra datada en 3,53 $\pm 0,04 \mathrm{Ma}$ (trazas de fisión in Marshall et al., 1979) y en 3,66 $\pm 0,05 \mathrm{Ma}$ (Ar/Ar de Latorre et al., 1997). Según Muruaga (1998), en el área de Villavil, esta tefra está ubicada 90 m encima del contacto con la Formación Corral Quemado (Fig. 3B).

La sucesión presenta evidencias paleoclimáticas que indican una creciente aridez hacia la parte superior; aparecen areniscas en cuerpos de canal de escaso relieve y potencia asociados a calcretos, depósitos de 'loess' y arenas eólicas acumuladas directamente sobre canales fluviales gravosos $\mathrm{y} / \mathrm{o}$ formando grandes dunas. Los conglomerados y arenas gruesas indican flujos mantiformes y con frecuencia hiperconcentrados. El área fuente ubicada al oeste tenía un relieve creciente y se encontraba justo en el borde de cuenca a juzgar por la presencia de depósitos de abanico aluvial distal y ríos enlazados gravosos, en el perfil del cerro El Durazno.

La presencia de restos de árboles asociados a paleosuelos (vertisoles) con rizoconcreciones y calcretos, fósiles de animales de variado porte (una combinación de grandes herbívoros y mirmecófagos) y arquitectura fluvial de ríos permanentes, indica que el clima era más húmedo que el actual y posiblemente una sabana de gramíneas (vegetación C3 en Latorre et al., 1997) salpicada de árboles y bosques en galería a lo largo de los ríos.

Un aspecto importante de la sedimentación de la Formación Andalhuala es la existencia de una disconformidad levemente angular en el terreno, que afecta el límite entre la sección superior e inferior en el valle de Santa María. Este límite se advierte en las fotografías aéreas del sector ubicado al frente de la ciudad de Santa María (ver figura 4 en Bossi et al., 2001). El diseño de los estratos presenta una deformación mayor en la parte inferior (Formaciones San José, Las Arcas, Chiquimil y sección inferior de Andalhuala), que disminuye hacia arriba hasta la disconformidad. Las capas que siguen encima tienen un desarrollo simple y homoclinal, buzante hacia el este. Es evidente que estas diferencias de estilo tectónico a ambos lados de la disconformidad intra Andalhuala, están relacionadas con la actividad de fallas durante la etapa de 'rifting'. Las líneas sísmicas del Campo del Arenal muestran numerosas fallas sinsedimentarias, que pierden rechazo hacia arriba.

La posición estratigráfica de esta disconformidad en el valle de Santa María está acotada entre las tefras 4,8 y 5,2 Ma ubicadas dentro de la Formación Andalhuala (fechadas por Strecker, 1987).

Entre Villavil y Puerta de Corral Quemado, el límite está definido por el cambio textural de areniscas a conglomerados. Sin embargo, en el cerro Pampa, el contacto con Formaciones Andalhuala y Chiquimil (Fig 3A), es una discordancia angular. Esta discordancia y el cambio de facies arenosas a 
conglomerádicas representan un equivalente austral de la discordancia intra Andalhuala. El nivel correspondiente, definido mediante las curvas de isótopos ambientales (Muruaga et al., 2003), en el depocentro de Villavil, corresponde al inicio de las facies conglomerádicas que definen el contacto entre las Formaciones Corral Quemado y Andalhuala, ubicado $90 \mathrm{~m}$ debajo de la tefra 3,66 Ma (Latorre et al., 1997).

En la parte sur de la Cuenca, más específicamente en el cerro Pampa, el contacto entre las formaciones Andalhuala y Corral Quemado es una discordancia angular, que no cuenta con dataciones radiométricas, pero cuya edad puede ser estimada a partir de las relaciones estratigráficas entre ambas unidades en el área de Villavil. Considerando las tasas de sedimentación determinadas por Butler et al. (1984) mediante magnetoestratigrafía en el vecino perfil de Corral Quemado, es posible inferir una edad entre 3,8-4 Ma para el contacto entre las formaciones Andalhuala y Corral Quemado, que resultaría más joven que la edad estimada para discordancia intra Andalhuala en el valle de Santa María.

2.2.2.4 Formación Corral Quemado. El término Corral Quemado aparece por primera vez como Horizonte Corral Quemado (Riggs y Patterson, 1939), para denominar la unidad cuspidal del Neógeno que involucra las secciones 18 a 32 del perfil de Stahlecker. Sin embargo, inspeccionando en detalle el Perfil de Stahlecker (in Marshall y Patterson, 1981), el límite litológico puede ser ubicado más arriba, justo debajo de los conglomerados de las secciones 28 y 29.

La unidad consiste en conglomerados finos clasto soportantes, en capas laminadas paralelas, con guijarros y guijones y bloques dispersos, en estratos tabulares de espesor irregular de 0,3 a $1,5 \mathrm{~m}$, que alternan con areniscas medias y finas en capas finas a medianas lenticulares y tabulares irregulares. Se intercalan escasas lentes de areniscas medianas en capas delgadas irregulares o lenticulares y algunos conglomerados matriz soportante. El espesor total en el área de Villavil-Corral Quemado es de $850 \mathrm{~m}$.

La unidad es elevada a rango de formación por Bossi et al. (1987 y 1993). Los estratos conglomerádicos de esta unidad pertenecen al Araucanense de González Bonorino (1950b) y son equivalentes a la sección superior de la Formación El Cajón de Turner (1962) y a la Unidad Superior de Allmendin- ger (1986) y la Subsecuencia IId del valle del Cajón (Bossi et al., 1993).

Los afloramientos siguen por el faldeo oeste del cerro el Durazno (occidental) y continúan hacia el SE hasta el río Las Lajas. Aflora en forma limitada al oeste de las localidades de El Eje y San Fernando y el cauce medio del río Loconte, cubierta discordantemente por el 'Punaschotter'. Corresponden también a esta unidad los afloramientos de conglomerados ubicados en el área del Tesoro, al pie del faldeo occidental de la sierra de Aconquija (borde oriental del Campo del Arenal) en contacto tectónico con el basamento cristalino mediante una falla inversa de alto ángulo.

Los mismos fósiles consignados para la Formación Corral Quemado se encuentran también en la Formación Andalhuala, tanto en la Puerta de Corral Quemado como en el valle de Santa María (Riggs y Patterson, 1939). Riggs y Patterson (1939) y Pascual y Odreman Rivas (1973), ubican la fauna exhumada en el Montehermosense. Las apreciaciones de edad de Butler et al. (1984) ubican el límite formacional entre Andalhuala y Corral Quemado muchos más abajo, en capas que corresponden a la Formación Andalhuala, en niveles con una edad estimada en 6,4-6,6 Ma (extraída de las figuras de sus perfiles). La tasa de sedimentación de $0,56 \mathrm{~m} / \mathrm{ka}$ de Butler et al. (1984) para la Formación Corral Quemado, aceptada por Allmendinger (1986), permite estimar la edad del tope de esta Formación. Considerando un espesor de $850 \mathrm{~m}$ (Muruaga, 1998), arriba de la tefra del Puerto, el tope puede tener una edad de 2,35 Ma, en el área de Corral Quemado. Con la datación realizada por Latorre et al. (1997), de 7,14 Ma para la misma tefra, el tope, según nuestros cálculos, estaría alrededor de 2,3 Ma. En el valle de Santa María la tefra ubicada en las capas cuspidales de la Formación Corral Quemado, adyacente a la falla con el basamento, tiene un fechado de 2,9 Ma (Strecker, 1987). Estos valores son suficientemente coincidentes para ubicar el fin de la sedimentación neógena en la Cuenca.

Sobre la base de estas consideraciones de edad la unidad puede ser asignada al intervalo Plioceno temprano-Plioceno tardío en la escala de Cowle y Bassett (1989).

El paleoambiente dominante es de abanico aluvial dominado por flujos diluidos y gravitatorios catastróficos. Las facies más comunes son conglomerados finos alternantes con arenas gruesas, for- 
mando dobletes bien estratificados que representan flujos mantiformes (Nemec y Postma, 1993). Estos tipos de abanicos con escasa participación de arcilla ocurren bajo clima árido con escasa meteorización de la roca madre, principalmente granítica (Blair y McPherson, 1994). Los conglomerados de esta unidad son facies proximales cuya petrografía corresponde a los bordes de cuenca inmediatos al este y oeste. La sucesión es sensiblemente granocreciente, lo que indica un progresivo aumento del relieve fuente/cuenca. El clima árido, más frío que el actual, favoreció la producción de abundante cascajo, además de la formación de dunas eólicas alimentadas por arena empujada por vientos australes, en este caso desde los bordes distales de los abanicos.

Las paleocorrientes en el área de Corral Quemado indican proveniencia del borde oeste de la cuenca. En el cerro Pampa, por su parte, la proveniencia es del S-ESE, o sea del basamento asociado a las actuales sierras de Belén, Ampujaco y cerro Pampa. Finalmente, en la ladera occidental de la sierra de Aconquija, la proveniencia es del este y sureste y las facies conglomerádicas son decididamente proximales.

\subsubsection{Punaschotter}

Punaschotter (Penck, 1920) es una denominación informal que involucra los conglomerados ubicados al sur de la localidad de Corral Quemado y que afloran extensamente desde el Durazno a ambos lados del cauce del río Loconte. Se trata de capas de conglomerados de textura fina a media y ocasionalmente gruesa, con guijones y bloques dispersos, de composición granítica y metamórfica, con rodados subredondeados con frecuentes pátinas negras, tabulares irregulares y lenticulares, que alternan con lentes de areniscas gruesas arcósicas o con fuerte contenido lítico. El espesor máximo no supera los $50 \mathrm{~m}$.

Estos conglomerados alcanzan la ribera derecha del río Los Nacimientos y a la altura de La Estancia yacen discordantemente sobre la Formación Corral Quemado (Bossi et al., 2001). Existen numerosos asomos de conglomerados de pie de monte que forman mesadas altas y que pueden asignarse a esta unidad. Sin embargo, la precisión estratigráfica involucrada es muy relativa, considerando la naturaleza conglomerádica, la procedencia cercana desde el basamento y la ausencia de fósiles. Los conglomerados de esta unidad tienen en común que conservan la superficie geomórfica superior y muestran escasa deformación. Sólo en el área de Corral Quemado, junto a la falla que levantó el bloque de la sierra de Papachacra, se observan estratos inclinados fuertemente que pertenecen a esta unidad.

En la quebrada de Amaicha y la parte inmediata a ésta, del valle de Santa María, aparece una unidad constituida por conglomerados, denominada Formación Yasyamayo (Fig. 3E2), que yace disconforme (o en discordancia angular) sobre las formaciones Andalhuala y Corral Quemado. En Bossi et al. (2001), esta unidad conglomerádica ha sido interpretada como producto del clímax de la inversión tectónica, etapa durante la cual comenzó la rápida elevación de los bloques de montaña aledaños a la cuenca.

Los depósitos del 'Punaschotter' pueden correlacionarse con la Secuencia III del valle del Cajón, denominada también Aloformación Totoral. Es también posible correlacionarlos con la Formación Yasyamayo (Fig. 3 E2) en el valle de Santa María. Bossi et al. (1999) les asignan una edad pleistocena temprana, que resulta consistente con las asignaciones de edad de Strecker (1987) y Kleinert y Strecker (2001) que ubican la Formación Yasyamayo entre su 'Pedimento II', presente en el valle de Santa María, datado en 1,2 Ma, y la parte alta de la Formación Corral Quemado, fechada en 2,9 Ma. La Formación Yasyamayo quedaría así ubicada dentro de estos límites temporales.

Los conglomerados han sido interpretados por Bossi et al. (2001) como depósitos acumulados durante el clímax de la inversión tectónica en espesores generalmente delgados sobre un pie de monte de relieve alto creciente y bajo un clima árido intenso. La aridificación del clima es sugerida por las relaciones isotópicas de $\delta^{13} \mathrm{C}$ y $\delta^{18} \mathrm{O}$ en calcretos, publicadas por Kleinert y Strecker (2001) y Muruaga et al. (2003). No hay generación de espacio de acomodación en este punto y la preservación se genera por efecto sombra (Bossi et al., 2001) al pie de los relieves emergidos o valles alimentadores de larga actividad (e.g., quebrada de Amaicha). El comportamiento sintectónico de la unidad queda evidenciado por la intensa deformación local y el desarrollo de discordancias progresivas (como las observadas en la boca de la quebrada de Arca Yacu), junto a fallas de rumbo norte-sur, con intensa actividad sinsedimentaria relativamente reciente. 


\section{Análisis de las Líneas Sísmicas}

La ex empresa estatal YPF nos permitió disponer de una copia de varias líneas sísmicas del valle de Santa María y algunas del Campo del Arenal. Estas son las líneas YPF 1549 (Fig. 8) YPF 1553, YPF 1538 e YPF 1542 (Fig. 9) que forman un cuadrado sin unión, en el extremo SE del Campo y la línea YPF 1603, que se encuentra en el valle de Santa María, un poco al norte de la quebrada de Amaicha (Fig. 4).

La interpretación de estas líneas con los contactos entre unidades y espesores, fue obtenida mediante correlación con los perfiles de superficie de Las Cuevas (Fig. 3C) y Barranca Larga (Fig. 3D) y un análisis de los diseños sísmicos que se observan entre secciones de planos reflectores y también por correlación regional con las líneas del valle de Santa María (Fig. 4) y los perfiles estratigráficos relevados en este valle (Fig. 3E).

Mediante la correlación de los elementos estratigráficos con los estructurales (fallas y pliegues) fue posible construir mapas isopáquicos para las Formaciones Hualfín, las Arcas y Chiquimil, que en gran medida muestran la progresión del relleno sedimentario del Campo del Arenal (Figs. 10A, 10B y 10C). Las Formaciones Andalhuala y Corral Quemado no están presentes en la parte central del Campo del Arenal. Sobre las unidades neógenas remanentes, yace discordantemente una sucesión de sedimentos holocenos fluviales con fuerte componente eólica de espesor generalmente reducido. Esta relación indica una etapa de fuerte erosión hídrica y eólica en el Campo del Arenal, durante el Plioceno Superior y Pleistoceno.

En cuanto a la geometría del relleno sedimentario en el subsuelo, se puede decir que tienen particularidades comunes y en todas se detecta el contacto sedimentitas/basamento cristalino, que se define como una superficie de no conformidad relativamente plana. Cerca del contacto con el Basamento, es posible observar un plano reflector muy intenso que estimamos corresponde al pasaje de las Formación Hualfín a la Formación Las Arcas. Este contraste de impedancia se lo atribuye a un brusco cambio de nivel de litificación en el pasaje entre las mencionadas formaciones que se advierte claramente en la superficie (Figs. 8 y 9). La correspondencia con paleosuelos de este nivel de reflectores fuertes (ver Dávila et al., 2005) es muy poco probable, considerando la casi ausente injerencia de estos niveles en la estratigrafía local.

La línea YPF 1549 orientada este-oeste y ubicada cerca del borde sur del Campo del Arenal, muestra fallas inversas manteando hacia el oeste, que originalmente fueron fallas planas normales ahora revertidas (Fig 11A). La posición del plano reflector intenso que marca el tope de la Formación Hualfín, indica en estas fallas espesores de sedimento mayores en el bloque colgante además del desarrollo de una estructura anticlinal. Se puede observar que la reversión no fue total y hay un punto (círculos grises en la figura 11B) donde el rechazo se hace cero (punto neutro). La evolución de la estructura previa a la inversión tectónica, mediante un progresivo 'backstripping' (descompactación retrogradante) se esquematiza en la figura 11C. Se han usado como niveles de referencia los topes de las formaciones: (1) Chiquimil, (2) Las Arcas y (3) Hualfín (niveles numerados en la figura 11C). El esquema de la figura 11C permite presumir que la tasa de estiramiento de la litosfera durante la sedimentación de estas tres unidades fue alrededor de $9 \%$, valor que no fue compensado totalmente durante la inversión tectónica iniciada con la depositación de la Formación Andalhuala. Estos efectos expansivos compensados luego durante la etapa compresiva de los elementos sedimentarios localizados en los valles y bolsones, explican la escasa relevancia que tiene la deformación en la actitud de la pila sedimentaria cenozoica, considerando el inusitado crecimiento del relieve, verificado en igual período.

La Línea YPF 1538 (Fig. 9A) es aproximadamente norte-sur y muestra la estructura del subsuelo del Campo de Arenal en su sector oeste. Esta línea muestra una reducción brusca de espesores en el extremo sur, que afectan principalmente a las Formaciones Hualfín y Las Arcas, relacionado con la persistencia de un umbral de basamento controlado por una falla normal que buza hacia el norte. Solamente la Formación Chiquimil supera este umbral. Los afloramientos de la ladera norte del cerro El Durazno (oriental) muestran conglomerados volcánicos en superficie equivalentes al Miembro El Áspero (ver mapa geológico en la figura 5).

Hacia el norte, la sucesión cenozoica aumenta de espesor alcanzando su máximo a la altura de la intersección con la línea YPF 1553. Al igual que en el caso anterior, las fallas normales afectan severamente el espesor de la Formación Hualfín, disminuyendo su 

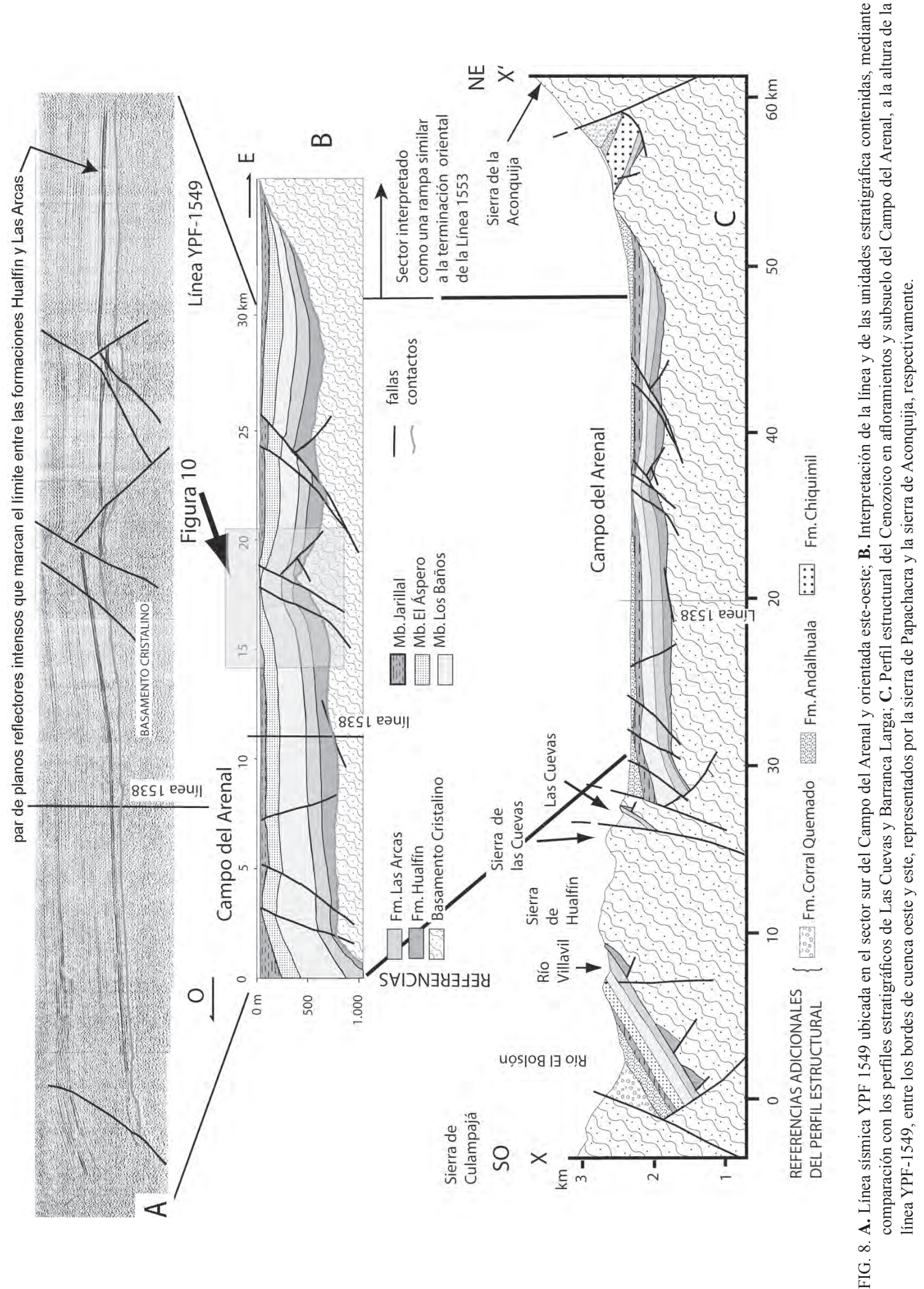

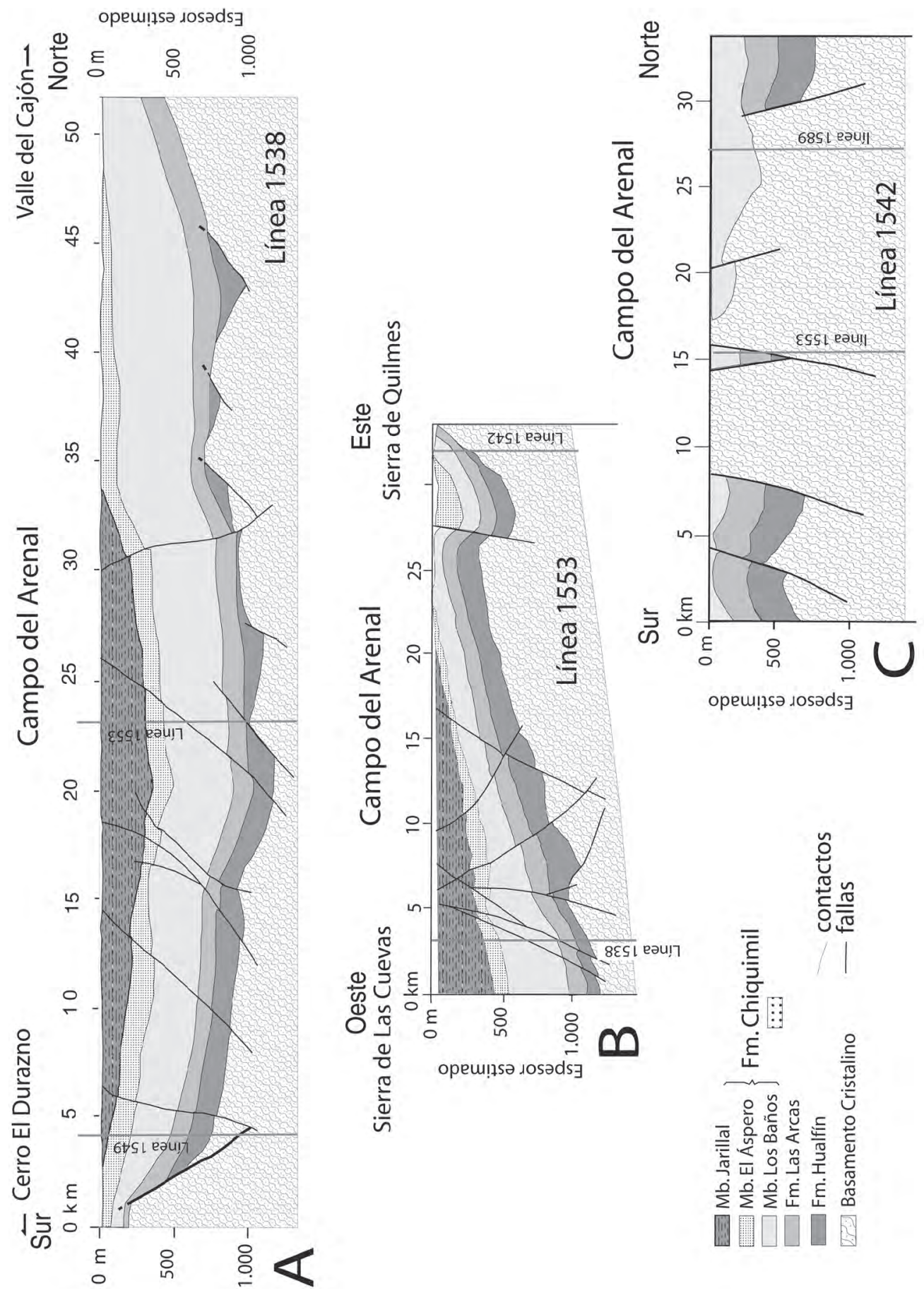

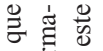

号

矛选

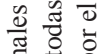

表 $\frac{\pi}{\pi}$

党.

ब

든 을

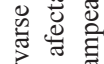

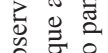

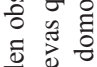

吾

总

热总

步覀

$\lambda$ 范

กิ

挖

$\rightarrow$ 을

负.

प्ट है

究焉

这官

施

范

of

毛苋

政

के

휴웡

苛 : 흉

$\pi$

혹 $\frac{\pi}{2}$ 貝

욤

貝蛋这

.0.

$\circ \%$

焉彭

氙豈崖

号苋苋

원 긍 웜

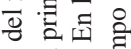

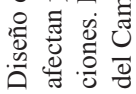

它 
influencia hacia arriba. En la línea YPF 1538 (Fig. 9A) no se observa ninguna estructura anticlinal de manera que la continuación del anticlinal central de la línea YPF 1549 no tiene correspondencia. La relación con el anticlinal que aparece en el extremo este de la línea YPF 1553 (Fig. 7B) es incierta, al no disponer los autores de las líneas sísmicas intermedias. La línea YPF 1553 cruza el campo de este a oeste en su parte norte, alcanzando en su extremo oriental los bordos que marcan la presencia del eje del domo pampeano. La línea YPF 1553 (Fig. 9B) presenta una terminación en rampa muy inclinada sobre el umbral de basamento cristalino que constituye la continuación de la sierra de Quilmes y divide el Campo en dos partes. La rampa en cuestión no es alcanzada por la línea YPF 1549 (Fig. 8A) de manera que la interpretación y el perfil estructural (Figs. $8 \mathrm{~B}$ y $8 \mathrm{C}$ ) contienen una rampa inferida a partir del comportamiento de la línea YPF 1553.

La línea YPF 1542 (Fig. 9C), dispuesta nortesur, corre prácticamente sobre los bordos (uso corriente en Argentina, para lomadas bajas que separan campos o planicies) que marcan un alto del basamento ubicado paralelo al eje del domo pampeano. Como puede observarse, el Basamento Cristalino está cerca de la superficie y el relleno sedimentario es de menor espesor y saltuario, controlado principalmente por fallas normales.

La línea YPF 1603 (Fig. 4) está ubicada fuera del mapa geológico (Fig. 5), en el valle de Santa María, un poco más al norte que la boca de la quebrada de Amaicha (Fig. 1), pero se ha incluido en este trabajo por su importancia en el análisis del relleno sedimentario. Esta línea muestra claramente un hemigraben desarrollado en una corta extensión este-oeste. Está implantado en poco más de $21 \mathrm{~km}$ en el subsuelo del valle de Santa María. Es imposible generar una flexión de la corteza rígida superior, constituida por rocas metamórficas, para acomodar en ese corto espacio $3.000 \mathrm{~m}$ de sedimentos como los consignados en su extremo oriental (espesores medidos en superficie), aun considerando un fuerte efecto de sobrecarga. Ninguna de las sierras limitantes alcanza a modificar su desarrollo. La sierra de Quilmes, en particular, está montada sobre el basamento pedimentado de su rampa. Las Cumbres Calchaquíes, por su parte, muestran en su pie, retazos del Neógeno limitados por fallas inversas, que corresponden a sectores marginales del hemigraben. Las divisiones en subsuelo han sido definidas a partir de los espesores medidos en superficie y los rasgos estructurales mapeados con mucho detalle.

La sedimentación del Neógeno estuvo relacionada con la actividad de fallas lístricas de crecimiento que se horizontalizan a profundidades no superiores a los 4-5 km, formando hemigrábenes con rampa común en el centro de la cuenca y depocentros junto a los bordes oeste y este, respectivamente.

La información de la línea YPF 1603, como también en otras que siguen más al norte, muestra este hemigraben partido en dos por una escama de basamento que trae a la superficie las unidades basales. Gran parte de la sierra de Quilmes y su continuación en el Campo del Arenal, constituyen la divisoria entre las vertientes occidental y oriental de la parte central de la cuenca, habiendo actuado de rampa común para los hemigrábenes de Santa María y El Cajón, cubierta por escasos sedimentos acumulados sobre un basamento pedimentado. En el inicio de la sedimentación neógena, el drenaje cruzaba desde el borde oeste de la cuenca en dirección al valle de Santa María, para luego en sucesivas etapas dirigirse hacia el sureste (Bossi et al., 2001), debido a la progresiva elevación de la sierra de Quilmes. Las líneas sísmicas que corren paralelas al valle de Santa María y conectan la línea YPF 1603 (Fig. 4) con las ubicadas en el Campo del Arenal (líneas YPF 1589 y 1572 no representadas), muestran claramente que no hay sedimentitas debajo del bloque de la sierra de Quilmes y el basamento yace sobre basamento, que en este último caso representa los restos de la rampa original.

\section{Mapas isopáquicos y perfil estructural}

La información brindada por las cuatro líneas sísmicas del Campo del Arenal y otras que entran en el valle de Santa María (las mencionadas líneas YPF 1603, Fig. 4, YPF 1572 e YPF 1589), combinada con datos aportados por mapeos de superficie, perfiles estratigráficos de detalle de áreas cercanas al Campo, como ser: valle de Santa María, cerro El Durazno, sierras de Hualfín, Las Cuevas, sierra del Durazno y valle del Cajón, ha permitido realizar mapas isopáquicos en cuatro estadios de relleno de la cuenca: 1) Hualfín, 2) Las Arcas, 3) Los Baños y 4) El Áspero. El Miembro Jarillal y las Formaciones Andalhuala y Corral Quemado, no tienen suficiente participación en el subsuelo del Campo del Arenal, para encarar la construcción de sus mapas. 
La figura 10A muestra el mapa isopáquico del Estadio Hualfín. En éste, es posible observar la sedimentación, controlada por fallas normales planas organizadas en cascada, dispuestas NO-SE, con rumbo casi diagonal a la orientación de las masas serranas actuales (sierras de Aconquija, Chango Real, Quilmes, Las Cuevas, Hualfín y del Durazno). El espesor máximo aparece recostado sobre la falla de crecimiento y no suele superar los $150 \mathrm{~m}$.

La figura10B presenta el Estadio Las Arcas. La sedimentación está controlada por algunas fallas normales que persisten del estadio previo y salvo en el valle del Cajón y Villavil, no supera los $250 \mathrm{~m}$. La organización de los depocentros es más extensa y las áreas de máxima acumulación se comunican entre sí. El Basamento pedimentado que forma el fondo de la cuenca, está casi totalmente cubierto.

La figura 10C muestra el Estadio Los Baños que implica un desarrollo con espesores crecientes hacia el borde oeste de la Cuenca y un arreglo en hemigraben. Numerosas fallas normales sinsedimentarias afectan parcialmente la depositación. Éstas están organizadas en dos direcciones NO-SE (heredadas de los estadios anteriores) y nuevas con dirección NNE-SSO. Los materiales provienen mayormente del borde oeste y del sector NO de la cuenca.

La figura 10D corresponde al Estadio El Áspero. En este caso se advierte que las direcciones de paleocorrientes medidas en el área de Villavil y Barranca Larga, son coincidentes con las direcciones de progradación de los diseños sísmicos observados en las líneas YPF 1538 e YPF 1553. Estos diseños inclinados que indican progradación de materiales hacia el Campo del Arenal, aparecen también en la línea YPF 1549. El diseño progradante indica un aporte mayor de sedimentos que lo que la subsidencia permite alojar en el piso de la cuenca. Tal situación parece corresponder a la etapa de máximo crecimiento de los volcanes intracuencales y de expansión térmica de la corteza superior. La escasa subsidencia asociada permitió el ingreso de grandes volúmenes de materiales volcanoclásticos psefíticos provenientes de la destrucción de los volcanes cercanos (Farallón Negro, cerro Las Ánimas, Puna Austral). La progradación observada en la línea YPF 1549 es originada en la orla de brechas volcanoclásticas que rodea el Complejo Volcánico Farallón Negro, ubicado al sur del Campo y que afloran parcialmente en ese sector. El abanico de progradación que muestran las líneas YPF 1538 e
YPF 1553 (Fig. 9), proviene de un centro volcánico ubicado fuera de la Cuenca y en la misma Puna. Como la unidad tiene un marcado diseño lobular de los espesores a partir de estas dos áreas de aporte, su mapa isopáquico es totalmente diferente al del Estadio Los Baños.

A partir de información de superficie y de datos de subsuelo correspondiente a la línea YPF 1549 (Fig. 8), se ha confeccionado un perfil estructural por el Campo del Arenal, que cruza desde Barranca Larga hasta el faldeo occidental de la sierra del Aconquija (Fig. 8C).

\section{Marco tectónico y evolución de la Cuenca Cenozoica}

Bossi et al. (2000) proponen por primera vez la posibilidad de que el relleno de las cuencas cenozoicas en las Sierras Pampeanas nordoccidentales estuvo relacionado con una extensión cortical en el Mioceno temprano, seguida de inversión tectónica que comienza aproximadamente a los $5 \mathrm{Ma}$. Dos trabajos posteriores mencionan esta posibilidad: Dávila y Astini (2003) proponen una extensión cortical en el Mioceno temprano en la parte sur de los Andes Centrales (Sierras Pampeanas de la Provincia de Córdoba), que permitió el adelgazamiento y debilitación de la corteza superior que crea las condiciones para la sedimentación y posterior compresión y elevación de los bloques de montaña. La idea de expansión en el Mioceno e inversión tectónica posterior en la Sierras Pampeanas, se discute también en Ramos et al. (2002). Contrapuesto a estas ideas aparece la opinión de Jordan (1995), quien postuló que estas cuencas yacen sobre la corteza continental de la placa sudamericana que fue deformada por fallamiento inverso y flexión del bloque yaciente, generando subsidencia. Esto implicaría un sistema de fallas inversas corridas sobre sus bloques hundidos con vergencia hacia el oeste y convergentes en profundidad hacia un plano de despegue en una faja plástica del substrato cristalino. Este esquema implica también: la existencia de sedimentos cenozoicos ubicados debajo de los grandes bloques de basamento sobreelevados, una resistencia a la flexión relativamente baja del basamento cristalino en cortas extensiones este-oeste y una deformación sensible del cenozoico junto al pie de monte asociada a fuerte acortamiento cortical y abundante participación de conglomerados. La premisa de que el efecto de so- 

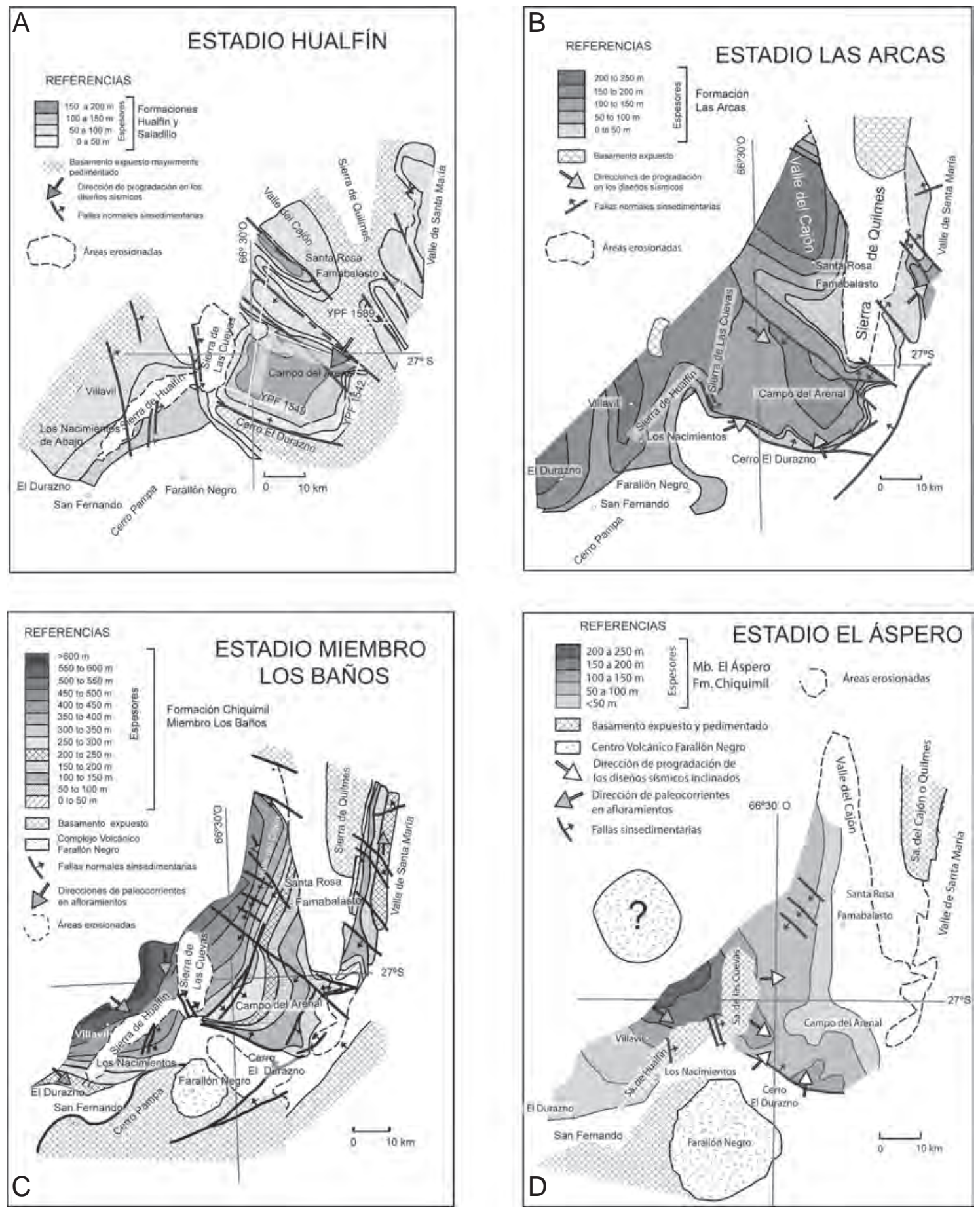

FIG. 10. Mapas isopáquicos del Campo del Arenal en los Estadios Hualfín, Las Arcas, Los Baños y El Áspero. Pueden ser observados los cambios de diseño de relleno que se discuten en el texto. 


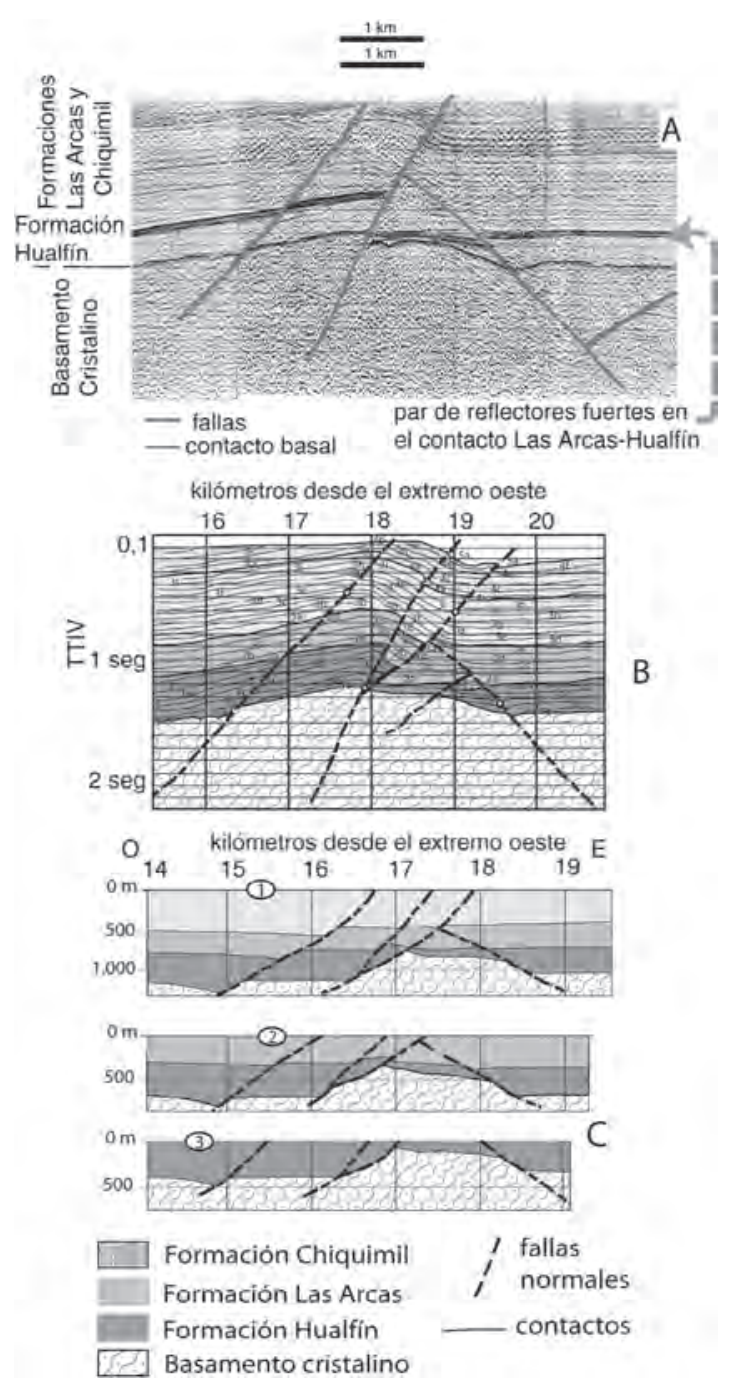

FIG. 11. Detalles e interpretación del anticlinal central de la línea YPF 1549. A. Sector de la línea sísmica; B. Interpretación y correlación de planos reflectores, con indicación de los puntos neutros; C. Esquema de descompactación progresiva en tres momentos que corresponden a tope de las formaciones Hualfín, Las Arcas y Chiquimil.

brecarga de cada bloque de basamento se adiciona a los ubicados más al este (antepaís fragmentado) implicaría tasas de subsidencia tectónica y de deformación y plegamiento (con efectos de canibalismo), crecientes hacia el borde oeste de la cuenca. Dávila et al. (2005), en un trabajo posterior, proponen, a su vez, para la gran cuenca de las Salinas Grandes, las Sierras Pampeanas en general y la llanura ChacoSantiagueña, procesos relacionados con un modelo de subsidencia regional de $>500 \mathrm{~km}$ de longitud de onda, inducido por flujos termodinámicos ocurridos en el manto astenosférico potenciado por subducción subhorizontal. Este comportamiento relacionado con un evento ocurrido en el Mioceno es de difícil predicción, aunque resulta aplicable en la formación del domo pampeano. Las Sierras Nordpampeanas difieren de las Sierras Pampeanas australes en la altitud general y menor extensión de las áreas deprimidas (valles y bolsones). En relación con este aspecto, Dávila et al. (2005) sostienen que las Sierras Pampeanas septentrionales están isostáticamente sobrecompensadas. Los esquemas de interpretación de las líneas sísmicas, presentados por Dávila et al. (2005), indicarían que toda la sedimentación ocurrió en una tectónica compresiva y la subsidencia ocurría por deflexiones asociadas a una subducción horizontal y desplazamientos astenosféricos. Este modelo no puede ser confirmado mediante la información existente en las Sierras Nordpampeanas, por los siguientes motivos:

- Existe un rasgo estructural importante en las Sierras Pampeanas que se conoce como penillanura (Fig. 6) y que ha sido mencionada repetidamente, aunque poco considerada en el análisis de la tectónica en el momento de formación de las cuencas. La penillanura es una superficie paleogeomórfica construida durante un período muy prolongado, que quizás abarca desde el Pérmico hasta parte del Paleógeno. Por el grado de peniplanización se puede inferir que la penillanura constituía una gran superficie o pedimento rocoso, de muy escaso relieve, que se extendía por toda el área pampeana de las provincias de Tucumán, Catamarca y parte de La Rioja. La penillanura es el piso sobre el cual se acumularon todos los sedimentos cenozoicos del área considerada, o sea, es un elemento de referencia fundamental en la historia del relleno de las cuencas terciarias de las Sierras Pampeanas. La penillanura está quebrada en numerosos bloques que muestran la superficie paleogeomórfica aplanada, aún preservada. Por este rasgo paleogeomórfico se puede establecer la inclinación y grado de basculamiento de los bloques del basamento pampeano, partiendo de un modelo inicial de una superficie peniplanizada ubicada topográficamente cerca del nivel del mar (Gavriloff y Bossi, 1992; Bossi et al., 2001). La forma de gran domo alargado de esta megaestructura fue avalada por gravimetría, la que se ajusta a una superficie de tendencia de $2^{\circ}$ orden (H. Gentz, comunicación personal, 1992). 
En muchos casos las Sierras Pampeanas (e.g., Quilmes, Velasco y Paimán) son estructuras de escamas apiladas, siendo la escama más joven la que se ubica debajo de toda la pila. En el caso de la sierra de Quilmes, las escamas están sólo parcialmente apiladas y no tienen una falla inversa continua al pie de ninguna de sus vertientes. Este caso como el de la sierra de Hualfín merece un párrafo aparte.

- La sierra de Quilmes en su tramo austral y la sierra de Hualfín tienen la penillanura desarrollada en ambas vertientes. Esto implica que la estructura se generó por ascenso a través de fallas de tipo 'pop-up' cuasi-verticales, con curvaturas opuestas hacia afuera del eje de la estructura. Es posible aceptar la alternativa de un basamento plegado para la sierra de Quilmes (aunque su radio de curvatura sería muy grande), pero no para el núcleo granítico de la estrecha sierra de Hualfín (Fig. 4), que tiene la penillanura perfectamente plana en ambas vertientes y en una de ellas llega hasta casi la cumbre.

- En la sierras de Velasco y Paimán el apilamiento es casi total. El manteo de la penillanura crece a medida que nos alejamos de la escama más joven $\left(11^{\circ}\right)$ y tiene un manteo mayor en la más vieja (en las sierras de Paimán y Vinquis es de $50^{\circ}$ ). Los bloques centrales tienen la penillanura prácticamente horizontal mientras que los alejados del eje central inclinan cada vez más hacia el este u oeste. El eje del domo cruza por el Campo del Arenal y sigue por la sierra de Capillitas para entrar en el sector oriental del bolsón de Pipanaco y luego cruza la sierra de Ambato, por la quebrada de la Cébila. La estructura del domo fue preservada durante la inversión tectónica que creó nuevas fallas y revirtió otras. El lineamiento Tucumán (Mon, 1976), que cruza diagonalmente la gran estructura dómica, está superpuesto a la misma produciendo un desplazamiento dextrógiro de las estructuras precedentes. Este lineamiento está ligado a un escalón móvil y profundo de la litosfera subyacente (Sasso y Clark, 1998) y tiene un papel destacado en el emplazamiento del gran estratovolcán de Farallón Negro (Mioceno Medio). En la figura 5 puede observarse la posición periclinal del cenozoico (y también la penillanura) alrededor del centro volcánico de Farallón Negro, producto de la expansión térmica. El borde occidental de la cuenca se extiende hacia el SSO, ya que afloramientos pertenecientes al Grupo Santa María, continúan hacia el sur desde el cerro El Durazno (occidental), la Hoyada de las Pailas y río Las Lajas, entre las sierras de Zapata y Fiambalá (localidades citadas en la figura 1).

- Las fallas inversas de las Sierras Pampeanas, ubicadas en el flanco oeste de esta gran estructura dómica, son en su mayoría reversiones de antiguas fallas inversas (Fig. 5). El diseño de estas fallas muestra muchas veces una vergencia hacia el centro del domo en superficie y posiblemente doblan e invierten su vergencia en profundidad. Del lado oriental del domo la mayor parte de las fallas inversas son nuevas y no tienen relación definida con la formación de las cuencas. En todos los casos las fallas son de alto ángulo y superan los $70^{\circ}$. Ramos et al. (2002) consideran probable un diseño de estas fallas similar al que propuso hace varias décadas González Bonorino (1972). La existencia de fallas de alto ángulo sin relación directa con la sedimentación es un aspecto fundamental en la interpretación de la relación sedimentitas/basamento cristalino. Es frecuente la publicación de perfiles estructurales con extensas 'colas de Terciario' (20 a $30 \mathrm{~km}$ ) debajo del basamento pampeano (González, 2000; Sobel y Strecker, 2003) o con fallas inversas controlando la acumulación de la sedimentación cenozoica. El perfil estructural (Fig. 8C) a la altura de la traza de la línea YPF 1549, muestra un extenso desarrollo del hemigraben occidental, que tiene su máximo espesor junto a la sierra de Papachacra, a la altura de Corral Quemado-Villavil.

- La línea YPF 1603 (Fig. 4) que ya fue discutida precedentemente y otras líneas transversales al valle de Santa María (e.g., la línea YPF 1617, frente a Tolombón en la parte norte del valle) definen la presencia de un relleno con un diseño de hemigraben, de escasa extensión en sentido este-oeste y en cuyo desarrollo no están involucrados los bloques de basamento de la sierra de Quilmes y las Cumbres Calchaquíes. El Campo del Arenal es el primero de los bolsones pampeanos que con un diseño equidimensional pueblan la región central del domo. Hacia el sur estos bolsones se hacen más extensos y aún hoy constituyen cuencas de acumulación activa (Bolsón de Pipanaco, Depresión de las Salinas 
Grandes, etc.). La sedimentación activa en el Campo del Arenal concluyó prácticamente con la inversión tectónica y la elevación de su piso a más de $1.500 \mathrm{~m}$ sobre el nivel del mar. Los hemigrábenes de los valles de Santa María y el Cajón siguen en el Campo del Arenal, con un desarrollo mucho mayor, en sentido este-oeste, de la rama occidental (Fig. 8).

- Existe otro efecto no explicado por el modelo de antepaís: el asincronismo marcado del levantamiento de las sierras. En la cuenca de Santa María-Hualfín hay sierras de naturaleza intracuencal elevadas casi al final de la inversión tectónica y otras son bordes de cuenca de larga persistencia durante la sedimentación que comenzaron a elevarse en varias etapas desde el inicio de la inversión tectónica. Esto queda evidenciado por el nivel de evolución de los abanicos de pie de monte y sus respectivas cuencas imbríferas. Por ejemplo, es marcada la asimetría de evolución de los abanicos del faldeo de la sierra de Aconquija, en el valle de Santa María, que comprende varias etapas de elevación y pedimentación (cinco en total) que involucran un lapso Pleistoceno inferior a Holoceno, comenzando a los 2,5 Ma con el primer nivel (Strecker, 1987; Kleinert y Strecker, 2001) y probablemente antes, con la acumulación en la quebrada de Amaicha de la Formación Yasyamayo. Las sierras de Aconquija y Cumbres Calchaquíes fueron borde de cuenca durante la totalidad de la sedimentación en el valle. Por el contrario, la sierra de Quilmes tiene sus abanicos orientales muy maduros y extensos, pero formados en una única etapa de evolución que quizás se extienda hasta el Pleistoceno superior. Estos abanicos corresponden topográficamente a los abanicos más jóvenes del faldeo oriental de la sierra de Aconquija (que pueden corresponder en edad a los Pedimentos IV y V, datados ca. 0,3-0,6 Ma por Strecker, 1987). Gran parte de la sierra de Quilmes es una estructura 'intracuencal' y actuó de derivador del drenaje desde el momento inicial de la inversión tectónica. La sierra se levantó a su actual altura, en tiempos relativamente recientes (Bossi et al., 2000). Las sierras de Chango Real y Papachacra y otras sierras 'intracuencales' como ser el cerro El Durazno (oriental), sierras de Hualfín y las Cuevas por el contrario, tienen varios niveles de piedemonte. Los más antiguos presentan diferentes grados de deformación y están representados estratigráficamente por el 'Punaschotter' (Penck, 1920) y la Secuencia III (Bossi et al., 1993, 1994, 1999 y 2001) del valle del Cajón y constituyen el borde occidental de la cuenca.

- Debe hacerse hincapié, en este punto, en el ambiente depositacional de las sedimentitas cenozoicas desde su contacto con el basamento hasta la discordancia intra Andalhuala. Considerando los depósitos cuya proveniencia es el Basamento Cristalino (excluida la participación de los volcanes del ciclo magmático de Farallón Negro), puede observarse el dominio de facies fluviales de llanura asociadas a varios eventos lacustres, con escasa participación de conglomerados. Los sistemas fluviales indican la presencia de ríos de llanura de régimen permanente. Este tipo de sedimentación está asociada con áreas fuentes de escaso relieve, que no presentaron indicios de crecimiento del relieve hasta el momento de la inversión tectónica. La rica fauna de herbívoros, algunos de gran tamaño, indica la presencia de extensas superficies cubiertas por pastizales en un ambiente de llanura, posiblemente con un clima de sabana. No existían barreras climáticas por el lado este de la cuenca, de manera que los vientos húmedos provenientes del Atlántico llegaban fácilmente, siendo posiblemente la Puna y los volcanes de la actual Cordillera de los Andes, la barrera final de éstos. Recién a partir de la discordancia intra Andalhuala se advierte una progresiva aridificación del clima. Los conglomerados son cada vez más frecuentes, con incremento de su textura y una reducción progresiva en su penetración en la cuenca durante el lapso Plioceno Superior a Pleistoceno Inferior (Formaciones Corral Quemado, Yasyamayo, 'Punaschotter', sucesivamente). La disminución de la actividad tectónica a partir de la construcción del plano de bajada más alto en el valle de Santa María (ca. 1,2 Ma, Strecker, 1987), determinó la acumulación de conglomerados de piedemonte de escaso espesor y una penetración limitada dentro de la cuenca. Esta etapa está relacionada con la inversión tectónica, con el ascenso de los bloques de basamento y la erección de barreras climáticas orientales

- Por la natural conformación de la Cuenca de Santa María-Hualfín, desarrollada por abovedamiento seguido de extensión, los depocentros se concentran junto a fallas lístricas que se 
horizontalizan rápidamente a profundidades de 4-5 km. Estas fallas marcaban inicialmente los bordes oeste (sierras de Chango Real, Papachacra, Culampajá y Zapata y Fiambalá) y este de la cuenca (sierras de Aconquija, Capillitas y Cumbres Calchaquíes). El análisis de los afloramientos localizados a lo largo de los depocentros occidental y oriental y de las líneas sísmicas que cruzan el Campo del Arenal (Fig. 5), muestra un relleno con un diseño de hemigrábenes someros con fallas lístricas que se horizontalizan a $4-5 \mathrm{~km}$ de profundidad. Los hemigrábenes tienen una rampa común, en un alto estructural del basamento, que cruza por el sector oriental del Campo del Arenal entre las sierras de Quilmes y Capillitas.

\section{Agradecimientos}

Este trabajo ha sido realizado en el marco de proyectos del CONICET y financiados por CIUNT (Universidad Nacional de Tucumán). Agradecemos la colaboración de S. Georgieff, M.E. Vides, J. Sanagua y L. Ibáñez (integrantes del IESGLO, Universidad Nacional de Tucumán) por su contribución en las tareas de campo y laboratorio. Agradecemos muy especialmente a los evaludores Dres. T. Jordan y L. Spalletti por su prolijidad en la corrección de este texto y al editor de la revista que contribuyó con apropiados comentarios finales.

\section{Referencias}

Allmendinger, R.W. 1986. Tectonic development, southeastern border of the Puna Plateau, northwestern Argentine Andes. Geological Society American, Bulletin 97: 1070-1082.

Bensel, C.A. 1986. Contribución al conocimiento geológico del sector comprendido entre el río Ampajango y la quebrada de las Trancas, Depto. de Santa María, Provincia de Catamarca. Seminario (Inédito), Universidad Nacional de Tucumán, Biblioteca de la Facultad de Ciencias Naturales: 78 p.

Blair, T.C.; McPherson, J.G. 1994. Alluvial fans and their natural distinction from rivers based on morphology, hydraulic processes, sedimentary processes, and facies assemblages. Journal of Sedimentary Research A64 (3): 450-489.

Bossi, G.E. 1969. Geología y estratigrafía del sector sur del Valle de Choromoro. Acta Geológica Lilloana 10: $17-64$

Bossi, G.E.; Villanueva, A.; Carrión, M.; Palma R.; Díaz, J. 1984. El Grupo Santa María en la Quebrada de Amaicha (Depto. Tafí, Pcia. de Tucumán). In Congreso Geológico Argentino, No. 9, Actas 1: 124. San Carlos de Bariloche.

Bossi, G.E.; Palma, R. 1982. Reconsideración de la estratigrafía del Valle de Santa María, Provincia de Catamarca, Argentina. In Congreso Latinoamericano de Geología, No. 5, Actas 1: 155-172. Buenos Aires.
Bossi, G.E.; Ovejero, R.; Strecker, M. 1987. Correlación entre los perfiles del Terciario superior en la Puerta de Corral Quemado-Hualfín y de Entre Ríos (Chiquimil). Provincia de Catamarca, Argentina. In Congreso Geológico Argentino, No. 10, Actas 2: 117-120. San Miguel de Tucumán.

Bossi, G.E.; Muruaga, C.; Sanagua, J.; Hernando, A.; Quiroga, G.; Ahumada, A.; Gavriloff, I. 1992. Aloestratigrafía del Neógeno del Valle del Cajón (Provincia de Catamarca). In Reunión Argentina Sedimentología No. 4, 3: 137-144. San Miguel de Tucumán.

Bossi, G.E.; Muruaga, C.M.; Sanagua, J.G.; Hernando, A.; Ahumada, A. 1993. Geología y estratigrafía de la cuenca Neógena Santa María-Hualfín (Departamentos Santa María y Belén, Provincia de Catamarca). In Congreso Geológico Argentino, No. 12, Actas 2: 156-165. Mendoza.

Bossi, G.E.; Georgieff, S.; Muruaga, C.; Sanagua, J.; Ahumada, A.; Ibáñez, L. 1994. The Santa MaríaHualfín Neogene Basin of northwestern Argentina. In International Sedimentological Congress, No. 14, Resúmenes G12-13. Recife, Brasil.

Bossi, G.E.; Muruaga, C.; Georgieff, S.; Ahumada, A.L.; Ibáñez, L.; Vides, M.E. 1997. The Santa María Neogene Basin of the Pampean Ranges: an example of mixed tectonic evolution. In Congreso Latinoamericano de Sedimentología, No. 1, Sociedad Venezolana de Geólogos 1: 97-104. Caracas.

Bossi, G.E.; Gavriloff, I.J.C.; Esteban, G. 1998. Terciario, Estratigrafía, Bioestratigrafía y Paleogeografía. In Geología del Tucumán (Giafrancisco, M.; Puchulu, M.E.; Durango de Cabrera, J.; Aceñolaza, G.F.; editores). Colegio de Graduados en Ciencias Geológicas de Tucumán, Publicación Especial: 87-108. San Miguel de Tucumán.

Bossi, G.E.; Muruaga, C.; Gavriloff, I.J.C. 1999. CicloAndino. Neógeno-Pleistoceno. Sedimentación(González Bonorino, G; Omarini, R.; Viramonte, J.; editores). In Congreso Geológico Argentino, No. 14, Relatorio 1: 329-360. Salta.

Bossi, G.E.; Georgieff, S.; Gavriloff, I.; Ibáñez, L.; Muruaga, C. 2001. Cenozoic evolution of the intramontane Santa María Basin, Pampean Ranges, northwestern Argentina. Journal of South American Earth Sciences 14: 725-734.

Butler, R.F.; Marshall, L.G.; Drake, R.E.; Curtis, G.H. 1984. Magnetic polarity stratigraphy and K-Ar dating of late Miocene and early Pliocene continental deposits, Catamarca province, NW Argentina. Journal of Geology 92: 623-636.

Cabrera, A. 1944. Los Gliptodontoideos del Araucaniano de Catamarca. Revista Museo La Plata (Nueva Serie) 3: 5-76.

Cowle, J.W.; Bassett, M.G. 1989. Global Stratigraphic Chart, with geochronometric and magnetostratigraphic calibration. International Union of Geological Science, Episodes (supplement) 12 (2).

Dávila, F.M.; Astini, R.A. 2003. Early Middle Miocene broken foreland development in the southern Central 
Andes: evidence for extension prior to regional shortening. Basin Research 15: 379-396.

Dávila, F.M.; Astini, R.A.; Jordan, T.E. 2005. Cargas subcorticales en el Antepaís Andino y la planicie pampeana: Evidencias estratigráficas, topográficas y geofísicas. Revista Asociación Geológica Argentina 60 (4): 775-786.

Flynn, J.J.; Swisher III, C.C. 1995. Cenozoic South American land mammal ages: correlation to global geochronologies. In Geochronology Time Scales and Global Stratigraphic Correlation (Berggren, W.A.; Kent, D.V.; Aubry, M.P.; Hordenbol, J.; editors). Society of Economic Paleontologist and Mineralogists, Special Publication 54: 317-333.

Galván, A.F.; Ruiz Huidobro, O. 1965. Geología del Valle de Santa María. Estratigrafía de las formaciones terciarias. Acta Geológica Lilloana 7: 217-230.

Gavriloff, I.J.C. 1999. Caracterización de la secuencia parálica neógena del Valle de Santa María (Catamarca, Tucumán y Salta, Argentina) y su relación con la ingresión marina paranaense. In Simposio Sul Brasileiro de Geologia, No. 7, Encontro de Geologia do Mercosul, No. 2, Abstracts: 77 p. Foz do Iguaçu.

Gavriloff, I.J.C.; Bossi, G.E. 1992. Revisión general, análisis facial, correlación y edades de las Formaciones San José y Río Salí (Mioceno medio), provincias de Catamarca, Tucumán y Salta, República Argentina. Acta Geológica Lilloana 17 (2): 5-43.

Gavriloff, I.J.C.; Bossi, G.; Esteban, G.; Nasif, N.; Musalem, S. 1998. El problema estratigráfico de la 'Edad'Mamífero Huayqueriense en la Cuenca Santa María-Hualfín (Catamarca, Tucumán y Salta). In Congreso Argentino de Paleontología y Bioestratigrafía, No. 7, Abstract: 128. Bahía Blanca.

González Bonorino, F. 1950a. Geología y Petrografía de las Hojas 12d (Capillitas) y 13d (Andalgalá). Boletín Dirección General de Industria Minera 70: 1-100. Buenos Aires.

González Bonorino, F. 1950b. Algunos problemas geológicos de las Sierras Pampeanas. Revista de la Asociación Geológica Argentina 5 (3): 81-110.

González, O. 2000. Hoja Geológica 2766-II. San Miguel de Tucumán. Boletín Servicio Geológico Minero Argentino, SEGEMAR 245: 123 p. Buenos Aires.

Groeber, P. 1929. Líneas fundamentales de la geología del Neuquén, sur de Mendoza y regiones adyacentes. Boletín Dirección General de Minas, Geología e Hidrología 58: 109 p.

Jordan, T. 1995. Retroarc Foreland and Related Basins. In Tectonics of Sedimentary Basins (Busby, C.J.; Ingersoll, R.V.; editors). Blackwell Science: 331362. Oxford.

Kleinert, K.; Strecker, M.R. 2001. Climate change in response to orographic barrier uplift: paleosol and stable isotope evidence from the late Neogene Santa María basin, northwestern Argentina. Geological Society of America Bulletin 113 (6): 728-742.

Kraglievich, L. 1934. La antigüedad pliocena de las faunas de Monte Hermoso y Chapadmalal, deducidas de su comparación con las que le precedieron y sucedieron. Imprenta ‘El Siglo Ilustrado’: 136 p. Montevideo.

Kraglievich, L. 1952. El perfil geológico de Chapadmalal y Miramar, provincia de Buenos Aires. Revista Museo Municipal de Ciencias Naturales 1: 8-37.

Latorre, C.; Quade, J.; McIntosh, W.C. 1997. The expansion of $\mathrm{C}_{4}$ grasses and global change in the table Miocene: stable isotope evidence from the Americas. Earth and Planetary Science Letters, Elsevier Science 146 (1-2): 83-96.

Linares, E.; González, R.R. 1990. Catálogo de edades radimétricas de la República Argentina 1957-1987. In Publicación Especial, Serie AB' (Didáctica y Complementaria). Asociación Geológica Argentina 19: 628 p.

Marshall, L.G.; Patterson, B. 1981. Geology and Geochronology of the Mammal-Bearing Tertiary of the Valle de Santa María and Río Corral Quemado, Catamarca Province, Argentina. FIELDIANA. Geology. New Series 9: 1-78.

Marshall, L.G.; Butler, R.F.; Drake, R.E.; Curtis, G.H.; Tedford, R.H. 1979. Calibration of the Great American Interchange. Science 204: 272-279.

Mon, R. 1976. La tectónica del borde oriental de los Andes, en las provincias de Salta, Tucumán y Catamarca, República Argentina. Revista Asociación Geológica Argentina 31 (2): 65-72.

Muruaga, C.M. 1998. Estratigrafía y Sedimentología del Terciario Superior de la Sierra de Hualfín, entre las localidades de Villavil y San Fernando, Provincia de Catamarca. Tesis Doctoral (Inédito), Universidad Nacional de Tucumán, Facultad de Ciencias Naturales e Instituto Miguel Lillo: 270 p.

Muruaga, C.M. 2001a. Estratigrafía del Miembro El Jarillal (Formación Chiquimil, Mioceno superior), la Sierra de Hualfín, Catamarca. Acta Geológica Lilloana 18 (2) : 265-280.

Muruaga, C.M. 2001b. Estratigrafía y desarrollo tectosedimentario de sedimentos terciarios en los alrededores de la Sierra de Hualfín, borde suroriental de la Puna, Catamarca, Argentina. Revista de la Asociación Argentina de Sedimentología 8 (1): 27-50.

Muruaga, C.M.; Sial, A.N.; Bossi, G.E. 2003. $\delta^{13} \mathrm{C}$ and $\delta^{18} \mathrm{O}$ distributions in the Cerro Pampa section (Santa María-Hualfín Basin, Catamarca, Argentina) and their paleogeographic implications. In South American Symposium on Isotope Geology, Short Papers B: 372-375.

Nasif, N.; Esteban, G.; Musalem, S.; Herbst, R. 1997. Primer registro de vertebrados fósiles para la Formación Las Arcas (Mioceno tardío), valle de Santa María, 
provincia de Catamarca, Argentina. Ameghiniana 34: 538.

Nemec, W.; Postma, G. 1993. Quaternary alluvial fans in southwestern Crete; sedimentation processes and geomorphic evolution. In Alluvial Sedimentation (Marzo, M.; Puigdefábregas, C.; editors). Blackwell 17: 235-276. Oxford.

Pascual, R.; Odreman Rivas, O. 1973. Las unidades estratigráficas del Terciario portadores de mamíferos. Su distribución y sus relaciones con los acontecimientos diastróficos. In Congreso Geológico Argentino, No. 5 (3): 293-338. Bahía Blanca.

Peirano, A. 1943. Algunos yacimientos de fósiles de la parte central del valle de Santa María y del valle del Cajón. Universidad Nacional de Tucumán, Cuadernos de Mineralogía y Geología 3: 1-9.

Peirano, A. 1945. Estudio Geológico de la Quebrada de Amaicha. Departamento Tafí, Provincia de Tucumán. Universidad Nacional de Tucumán, Cuaderno de Mineralogía y Geología 4: 1-62.

Peirano, A. 1956. Observaciones generales sobre la tectónica y los depósitos terciarios del cuadrángulo $26^{\circ} \mathrm{S}$, $64^{\circ} 30^{\prime} \mathrm{O}, 28^{\circ} 30^{\prime} \mathrm{S}, 67^{\circ} \mathrm{O}$ en el Noroeste Argentino. Acta Geológica Lilloana 1: 1-60.

Penck, W. 1920. Der Südrand der Puna de Atacama (NW Argentinien). Ab Handlungen MathematischPhysiakalische Klasse der Sächsischen Akademie der Wissens-chaften 37: 1-420. Leipzig, Alemania.

Powell, J.E.; Mulé, P.; Duarte, R.; Ortiz, P.; Sanagua, J.; Muruaga, C. 1998. Mamíferos de la Formación Chiquimil (Mioceno Superior) de la vertiente occidental de la Sierra de Hualfín, Provincia de Catamarca. Acta Geológica Lilloana 18 (1): 178.

Proffett, J.M. 1995. Geology of the Bajo de la Alumbrera Porphyry Copper-Gold deposits, Catamarca Province, Argentina. Minera Alumbrera Internal Report: 85 p. Anchorage, Alaska.

Ramos, V.A.; Cristallini, E.; Pérez, D. 2002. El levantamiento diacrónico de las Sierras Pampeanas en la zona de subducción horizontal. In Congreso Geológico Argentino, No. 15, Actas en CD-ROM: 72. El Calafate.

Riggs, E.S.; Patterson, B. 1939. Stratigraphy of late Miocene and Pliocene deposits of the Province of Catamarca (Argentina). Physis 14: 143-162. Buenos Aires.

Rosello, E.A.; Mozetic, M.E.; López de Luchi, M.G. 1999. El basalto de la Puerta de San José (Belén,
Catamarca): un nuevo testimonio del 'rifting' cretácico en el noroeste Argentino. In Congreso Geológico Argentino, No. 14, Actas, 2: 194-199. Salta.

Sasso, A. 1997. Geological Evolution and metallogenic relationships of the Farallón Negro Volcanic Complex, NW Argentina. Ph.D. Thesis (Unpublished), Queens University: 268 p. Kingston, Ontario, Canadá.

Sasso, A.M.; Clark, A.H. 1998. The Farallón Negro Group, northwest Argentina: magmatic, hydrothermal and tectonic evolution and implications fot $\mathrm{Cu}-\mathrm{Au}$ metallogeny in the Andean back-arc. Society of Economic Geologist, Newsletter 34: 6-18.

Segovia, M.F. 2004. Estratigrafía del faldeo occidental del Cerro Pampa al sur del Río Quillay, provincia de Catamarca. Seminario (Inédito), Universidad Nacional de Tucumán, Facultad de Ciencias Naturales: 56 p.

Simpson, G.G. 1974. Notes on Didelphidae (Mammalia, Marsupialia) from the Huayqueriense (Pliocene) of Argentina. American Museum Novitates 2559: 1-15.

Sobel, E.R.; Strecker, M.R. 2003. Uplift, exhumation and precipitation: tectonic and climatic control of Late Cenozoic landscape evolution in the northern Sierras Pampeanas, Argentina. Basin Research 15: 431-451.

Sosic, M. 1972. Descripción geológica de la Hoja 14dTinogasta. Boletín Dirección Nacional de Geología y Minería 129: 70 p. Buenos Aires.

Stipanicic, P.; Linares, E. 1975. Catálogo de edades radimétricas determinadas para la República Argentina. I años 1960-1974. Asociación Geológica Argentina, Publicación Especial Serie AB’ 3: 45 p.

Strecker, M.R. 1987. Late Cenozoic landscape development, the Santa María Valley, Northwest Argentina. Ph.D. Thesis (Unpublished), Cornell University: 261 p. Ithaca, New York.

Turner, J.C. 1962. Estratigrafía de la región al naciente de la Laguna Blanca, Catamarca. Revista Asociación Geológica Argentina 17 (1-2): 11-46.

Turner, J.C. 1973. Descripción geológica de la hoja 11dLaguna Blanca. Servicio Nacional Minero Geológico 142: 1-70. Buenos Aires.

Urreiztieta, M.; Rosello, E.A.; Gapais, D.; Le Corre, C.; Cobbold, P.R. 1993. Neogene dextral transpression at the southern edge of the Altiplano-Puna (NWArgentina). International Symposium on Andean Geodynamics No. 2: 267-269. 